\title{
Geographic variation in the foraging behaviour, diet and chick growth of rockhopper penguins
}

\author{
Yann Tremblay*, Yves Cherel \\ Centre d'Etudes Biologiques de Chizé, UPR 1934 du Centre National de la Recherche Scientifique, BP 14, \\ 79360 Villiers-en-Bois, France
}

\begin{abstract}
The foraging ecology of rockhopper penguins was investigated at 3 sites marked by contrasting ecological conditions. The northern subspecies was studied at Amsterdam Island (AMS) in oceanic subtropical waters, and the southern subspecies at the Kerguelen Archipelago (KER) in a subantarctic coastal habitat and at the Crozet Archipelago (CRO) in subantarctic neritic waters. During the brooding period, females from every site mainly made daily foraging trips lasting 11 to $12 \mathrm{~h}$. A principal component analysis (PCA) on 22 variables of daily foraging trips reduced these variables to 3 principal components, which were related to diving mode (PC1), foraging effort (PC2) and variation in diving behaviour (PC3). Overall, PC1 indicated that birds from AMS dived shallower, had shorter dive duration and bottom time, and were less active during less efficient dives than birds from KER and CRO. On the other hand, PC3 showed that birds from KER segregated from those of AMS and CRO by performing more uniform foraging trips with less variability in dive parameters. The PCA emphasised that most of the characteristics of daily trips and all the characteristics of foraging dives varied according to the study sites, thus stressing the importance of distinct environments in shaping the foraging behaviour of seabirds. Food loads, and accordingly chick growth, were lower at AMS, medium at CRO and higher at KER, while indices of foraging effort presented little variation. Birds at AMS fed mainly on the euphausiid Thysanoessa gregaria and on larger juvenile squids, while birds from CRO and KER preyed upon the subantarctic krill Euphausia vallentini. Diving strategies together with food loads and chick growth rates suggest that prey availability was low at AMS, intermediate at CRO and high at KER, which is in agreement with previous data on chlorophyll concentrations and zooplankton biomass. The study shows the complexity of foraging behaviour of penguins. It illustrates the importance of behavioural plasticity and suggests that it is a fundamental trait of the life history of seabirds living in highly variable environments.
\end{abstract}

KEY WORDS: Behavioural plasticity $\cdot$ Coastal $\cdot$ Diving behaviour $\cdot$ Thysanoessa gregaria $\cdot$ Eudyptes chrysocome $\cdot$ Oceanic $\cdot$ Neritic $\cdot$ Euphausia vallentini

\section{INTRODUCTION}

An animal's foraging behaviour is constrained by its morphological and physiological specialisation for feeding. Within these limits many species show considerable foraging plasticity in response to fluctuations in both abiotic and biotic conditions, or to changes in their energetic needs or the different stages of the annual cycle (reproduction, migration, moult). Sources of variation in foraging behaviour of birds are multiple and complex (Morrison et al. 1990). For example, foraging characteristics of penguins, the most abundant avian consumers in the Southern Ocean (Woehler 1995), vary according to light (Wilson et al. 1993), the presence of sea-ice (Watanuki et al. 1997), prey abundance and availability (Watanuki et al. 1993), breeding stage and energy demands (Charrassin et al. 1998), and seasons and years (Clarke et al. 1998, Moore et al. 1999). This suggests that the foraging behaviour of penguins is quite variable and flexible in response to the mobility and 3-dimensional distribution of their prey.

For many animal species, geographically separate populations experience markedly different ecological 
conditions. Comparison of different populations can therefore provide a valuable method for identifying causes of adaptive differentiation or phenotypic plasticity. One group of organisms that is well suited to this type of investigation is penguins. Like many seabirds, penguins are strongly philopatric, often breed on isolated islands, yet some species have a broad geographic range (Williams 1995). Moreover, studies on the foraging ecology of diving animals has been revolutionised over the last decade by the use of miniaturised electronic time-depth recorders (TDRs) that allow detailed descriptions of at-sea behaviour (Wilson 1995). This provides an opportunity to investigate how different populations of the same species change their diving pattern according to different marine habitats. Nevertheless, only a few studies have dealt with spatial variations in the foraging ecology of penguins (Kirkwood \& Robertson 1997a, Watanuki et al. 1997, Radl \& Culik 1999).

We chose the female rockhopper penguin Eudyptes chrysocome during the brooding period as a model for several practical and ecological reasons:

(1) In the Southern Indian Ocean, rockhopper penguins breed both in the warm waters of the Subtropical Zone (Amsterdam Island) and in the colder water of the Polar Frontal Zone (Crozet and the Kerguelen Islands) (see Park et al. 1993 for hydrography). Different populations thus forage in different water masses, feed on different prey (Cooper et al. 1990, Ridoux 1994, Cherel et al. 1999) and show contrasting plasticity in their diving behaviour (Tremblay \& Cherel 2000).

(2) During the brooding period, females feed the offspring while males fast ashore, guarding the chicks. Consequently, chick growth depends on provisioning rates by the female. The picture is not complicated by gender differences in the foraging ecology of adult birds (Bethge et al. 1997, Clarke et al. 1998).

(3) During the brooding period, females make daily foraging trips, feeding at that time in the immediate vicinity of the colonies and spending the night ashore (Warham 1975, Cherel et al. 1999, Tremblay \& Cherel 2000). This behaviour permits characteristics of foraging trips to be recorded by fitting different females with TDRs at a high turnover rate. Previous work on the diving behaviour of penguins has often included just a few trips carried out by a relatively small number of birds (Bengtson et al. 1993, Croxall et al. 1993, Kooyman \& Kooyman 1995, Bethge et al. 1997, Peters 1997, Wilson et al. 1997).

\section{MATERIALS AND METHODS}

Birds and study sites. Brooding females of rockhopper penguins were studied at 3 localities in the South- ern Indian Ocean (Fig. 1). Fieldwork on the northern subspecies Eudyptes chrysocome moseleyi was conducted in October to November 1996 at Pointe d'Entrecasteaux (375' $\left.\mathrm{S}, 77^{\circ} 31^{\prime} \mathrm{E}\right)$, Amsterdam Island (AMS), and on the southern subspecies (E. C. filholi) in January to February 1998 \& 1999 at Mayes Island $\left(49^{\circ} 28^{\prime} \mathrm{S}, 6^{\circ} 56^{\prime} \mathrm{E}\right)$, Kerguelen Archipelago (KER), and Pointe Basse $\left(46^{\circ} 21^{\prime} \mathrm{S}, 51^{\circ} 42^{\prime} \mathrm{E}\right)$, and Possession Island, Crozet Archipelago (CRO), respectively (Fig. 1). Birds from AMS foraged in temperate oceanic subtropical waters $\left(\approx 14^{\circ} \mathrm{C}\right)$. The island is located north of the Subtropical Front and is devoid of any peri-insular shelf. By contrast, at KER and CRO, penguins feed in the cooler waters $\left(\approx 7^{\circ} \mathrm{C}\right)$ of the Polar Frontal Zone (Park et al. 1993). Those from KER foraged in shallow and sheltered coastal waters in the Golfe du Morbihan, and those from $\mathrm{CRO}$ in more open and deeper (neritic) waters, over the shelf surrounding the Archipelago (Fig. 1). Penguin food availability was not recorded in this study, but the differences in physical features are likely to influence marine biomass and productivity between sites. During the study periods, chlorophyll concentrations were $>1.3,0.3$ to 0.5 and 0.2 to $0.4 \mathrm{mg}$ $\mathrm{m}^{-3}$ in the Golfe du Morbihan (KER), and at CRO and AMS respectively (SeaWIFS project: http://daac.gsfc. nasa.gov/). Accordingly, previous studies have shown that zooplankton biomass was higher in inshore than in offshore subantarctic waters, and higher in subantarctic than in subtropical waters (Foxton 1956, Razouls et al. 1997, Labat et al. 2002). We thus expected decreased food availability for penguins in the order KER, CRO and AMS.

General procedures. Special care was taken to study birds using the same materials and the same protocols at the 3 different localities. At each site, 2 closely situated colonies of rockhopper penguins were used. One was used for investigating the female foraging ecology (foraging colony), and one for quantifying the humaninduced effects on chick growth (control colony). Nests were numbered with sticks or painted rocks, with colonies carefully mapped before hatching began.

In the foraging colonies, females were opportunistically selected and captured in the early night hours, after chick feeding. They were measured, weighed (accuracy $\pm 25 \mathrm{~g}$ ), fitted with TDRs, and released at their nest 15 to $20 \mathrm{~min}$ following capture. This timing allowed females to recover from the stress of capture and manipulation overnight before returning to sea to feed. The diving behaviour was recorded over about 3 consecutive days per individual bird. On their return ashore, the females were recaptured before they reached their nests to avoid disturbance of males and chicks. The TDRs were removed, birds were weighed, and stomach contents of some individuals were obtained by water off-loading (Gales 1987). No females 


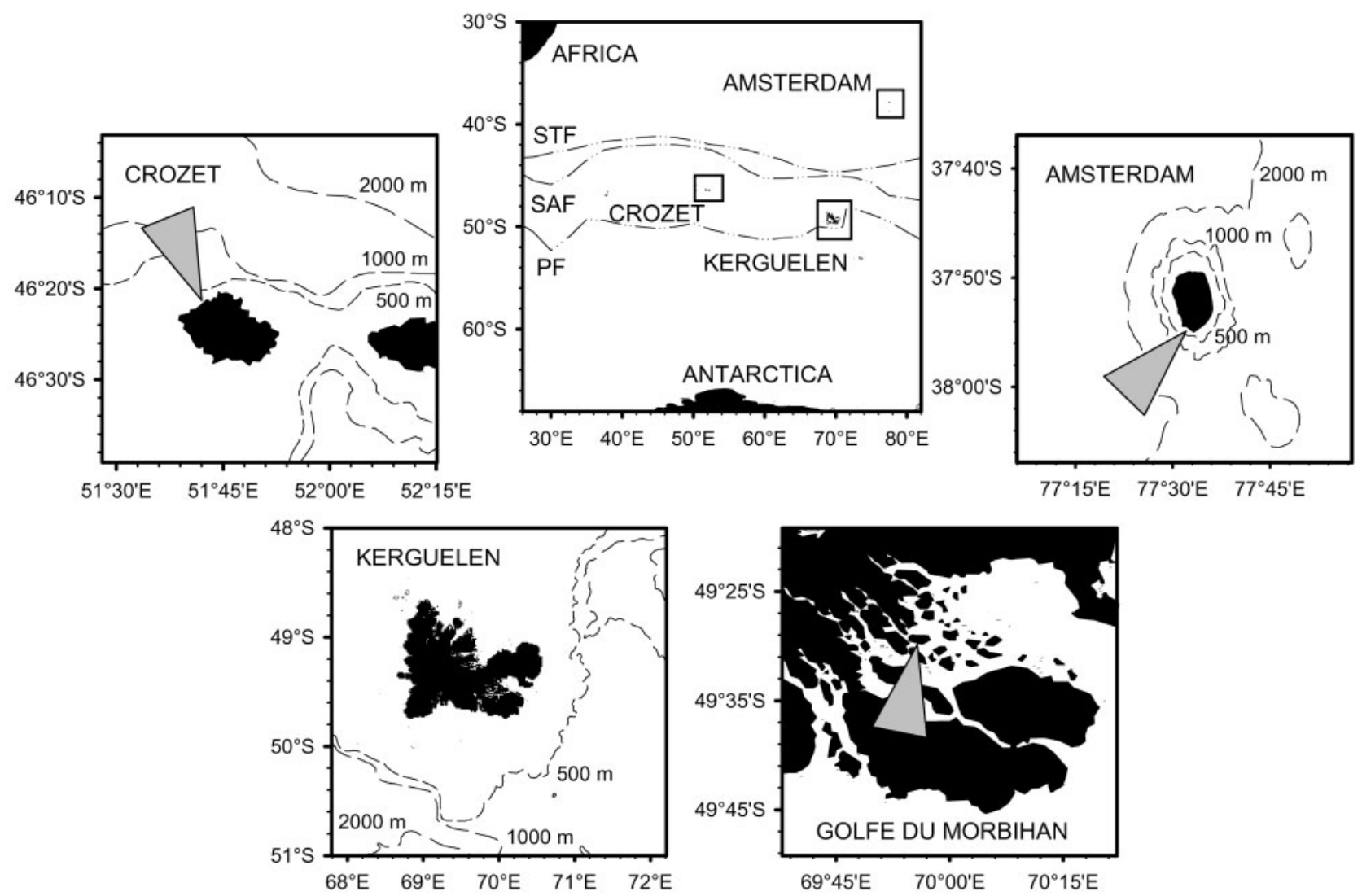

Fig. 1. Maps of Southern Indian Ocean showing the 3 study sites: Pointe d'Entrecasteaux (Amsterdam Island, AMS), Mayes Island (Golfe du Morbihan, Kerguelen Archipelago, KER) and Pointe Basse (Possession Island, Crozet Archipelago, CRO)

were fitted with TDRs and no stomach contents sampled in the control colonies.

In both foraging and control colonies, chicks were weighed every $5 \pm 1 \mathrm{~d}$ during the complete brooding period and during the early- to middle-crèche stage. Weighing was performed in the middle of the day to avoid disturbance of the foraging adults that were at sea at this time. To recognise chicks in crèches, individual birds were banded with a Velcro band and/or a number was engraved on the tip of their beaks.

Chick growth and hatching date. As for chinstrap penguins Pygoscelis antarctica (Meyer et al. 1997), growth of individual chicks was approximately linear during the brooding period $\left(\mathrm{R}^{2}=0.96 \pm 0.06, \mathrm{n}=345\right)$. The coefficient of the regression lines thus represented growth rate (i.e. the daily increase in body mass), expressed in $g$ per day.

For some nests, hatching date was determined visually and the mass of chicks at hatching recorded. Due to the high number of chicks studied ( $\mathrm{n}=71,147$ and 127 at AMS, KER and CRO respectively), the duration of the hatching period (about $10 \mathrm{~d}$ ), and the potential level of disturbance in the colonies, we were unable to determine hatching dates at all nests. They were therefore estimated graphically by the extension (back in time) of the regression line of chick mass against date until the average mass at hatching was reached (accuracy $\pm 1 \mathrm{~d}$ )

Dietary analysis. Stomach flushing was repeated until the water ejected from penguins contained no food material and was totally clear (Gales 1987); this required generally 3 to 4 stomach lavages. Females were then released at their nest to recover from the stress of manipulation. Food samples were drained and kept frozen for later laboratory analysis at Chizé, France.

In the laboratory, food analysis was performed following Tremblay et al. (1997). Briefly, stomach samples were thawed, drained and weighed. Species composition of the food was determined from otoliths and bones of fish, beaks of squid, and eyes and exoskeletons of crustaceans. Total numbers of euphausiids were extrapolated from counts of eyes performed in sub-samples to the whole sample mass (3 sub-samples weighing $3 \mathrm{~g}$ each). Fish and squid were sorted and counted from the whole sample. Accumulated items, including squid beaks, were excluded from subsequent analyses. Prey were identified using keys from 
Baker et al. (1990), Ledoyer (1995), and Schneppenheim \& Weigmann-Haass (1986), and by comparison with material held in our own reference collection.

TDRs. Diving behaviour was studied using electronic TDRs (Mark V, Wildlife Computers). The instruments were $9.5 \mathrm{~cm}$ long $\times 3.7 \mathrm{~cm}$ wide $\times 1.5 \mathrm{~cm}$ high, and weighed $70 \mathrm{~g}$ in air, corresponding to about $3 \%$ of the bird's body cross-sectional area and $<3 \%$ of body mass. Because non-streamlined devices have deleterious effects on crested penguins (Hull 1997), TDRs were shaped following information given in Bannasch et al. (1994). The streamlined TDRs were attached to the most caudal position on the back of the birds using quick-set epoxy adhesive and plastic ties (Kooyman et al. 1992), i.e. in a way that minimizes disturbance (Ballard et al. 2001). The TDRs contained either 128- or 512-kilobyte memories. They were programmed to sample depth every $2 \mathrm{~s}$ (at depth $\geq 2 \mathrm{~m}$ ). The recording interval for depth was $<10 \%$ of the mean dive duration, and thus could not lead to errors in dive number and dive parameters (Wilson et al. 1995). Depth resolution was $\pm 1 \mathrm{~m}$.

Data analysis and statistics. Data analysis was performed using our own software (Tremblay \& Logette unpubl.) and following Tremblay \& Cherel (2000). We determined dive depth, dive duration, bottom time (the amount of time between 75 and $100 \%$ of the maximum depth reached, during which predators presumably feed), diving efficiency (bottom time/[dive duration + post-dive interval]; Ydenberg \& Clark 1989), and descent and ascent rates for individual dives. Descent and ascent rates could not be calculated accurately for depths $\leq 5 \mathrm{~m}$, as a result of methodological artefacts arising from the TDR's programming (Cherel et al. 1999). Activity indexes were defined while the bird was at the bottom of the dive. First, we counted zigzags in depth (depth wiggles) at this time; second, we measured differences in depth between consecutive records, summed all these differences, and divided the sum by bottom time (depth-activity index). We also measured the time interval between bottom times as the duration between the end of the bottom time for a given dive and the beginning of the bottom time for the subsequent dive.

A dive was considered for analysis when the maximum depth was $\geq 3 \mathrm{~m}$ (Chappell et al. 1993). Various and varying criteria have been used to distinguish foraging dives from travelling (non-foraging) dives in penguins, the criteria depending both upon the authors and on the penguin species investigated. In the present study, an important and well-defined mode in the frequency distribution of dive depth was observed for depths $\leq 5 \mathrm{~m}$ at the 3 study sites $(20.4,14.6$ and $15.4 \%$ of the dives at AMS, KER and CRO respectively), thus enabling us to use a simple criterion to define foraging dives as dives reaching depths $>5 \mathrm{~m}$. To assess whether or not birds tended to dive serially to a specific depth, consecutive dives that returned within the same depth zone were called intra-depth zone (IDZ) dives. According to the difference in vertical distance recorded in 2 rockhopper penguins foraging within the same patch (Tremblay \& Cherel 1999), depth zone was defined as the depth $\pm 10 \%$ of the maximum depth reached by the preceding dive (Tremblay \& Cherel 2000). Following Horning \& Trillmich (1997), we also calculated the total vertical travel distance (VTD) during the foraging trips as the sum of dive depths from all dives multiplied by 2 .

Two statistical problems frequently arose from the analysis of dive data. Firstly, successive dives were partially autocorrelated (i.e. data were temporally pseudoreplicated, Hurlbert 1984). Secondly, not all animals have an equal statistical weight because of the unequal number of foraging trips recorded per animal and the different number of dives per trip. To overcome these problems, we did a partial autocorrelation analysis, which verified the degree of autocorrelation within our temporal series of data. The analysis showed that maximum depth of dives lost correlation after 4 successive dives. Since the lowest number of dives recorded for 1 individual penguin was 282, we randomly selected 50 dives per bird. The resulting data set (5950 dives) was used to analyse the characteristics of the dives at the different localities $(2050,1900$ and 2000 dives at AMS, KER and CRO respectively).

Foraging ranges, i.e. horizontal distances moved away from the colony, were estimated from the time between the first recorded dive and the first group of at least 3 consecutive dives $\geq 10 \mathrm{~m}$, assuming that penguins travelled continuously at a constant travelling speed of $7.4 \mathrm{~km} \mathrm{~h}^{-1}$ (Brown 1987a) and in a straight line. Similarly, the time between the last 3 consecutive dives $\geq 10 \mathrm{~m}$ and the last dive was calculated for the return journey (Cherel et al. 1999). During these first and last periods of foraging trips, most of the consecutive dives were $\leq 5 \mathrm{~m}$, indicating that birds were mostly travelling. Because luminosity is already high at sunrise and still elevated at sunset, daytime was calculated (following the nautical definition of dawn and dusk, i.e. when the sun is $12^{\circ}$ below the horizon) as the time elapsed from dawn (45 min before sunrise) to dusk (45 min after sunset).

Data were analysed using SYSTAT 7.0. Means ( \pm SD) are given. When individual birds represented more than 1 record in the data set from 1 study site (for example, several foraging trips from the same female), a nested-ANOVA was performed, and the F-test of geographic sites (AMS, KER and CRO) was constructed, with the mean square of birds nested within sites, as the error term. Post-hoc Bonferroni tests were used to 
make pairwise comparisons when an ANOVA showed a significant difference. Standard analysis of covariance (ANCOVA) was used to compare intercepts and slopes of regression lines.

\section{RESULTS}

\section{General}

Overall, 119 female rockhopper penguins were fitted with TDRs during the 3 consecutive field seasons. All the birds went back to the colony apparently in good health and in time, meaning no nest desertion resulted and, accordingly, no loss of electronic devices.

Foraging ecology was investigated during a period of 21, 21 and 19 consecutive days from 41, 38 and 40 birds at AMS, KER and CRO respectively. This allowed the recording of 380 whole foraging trips ( $\mathrm{n}=$ 119, 123 and 138 at AMS, KER and CRO respectively), which included a total of 152433 dives $\geq 3 \mathrm{~m}$ during $4967 \mathrm{~h}$ at sea $(\mathrm{n}=62470,42971$ and 46992 dives during 1734, 1458 and $1775 \mathrm{~h}$ at sea at AMS, KER and CRO respectively). Food samples were collected from 97 females $(\mathrm{n}=34,36$ and 27 at AMS, KER and CRO respectively).

\section{Foraging pattern, foraging range and dive frequency}

Most of the foraging trips made by female rockhopper penguins were completed on the same day, but some of them were longer, generally including 1 night ( $\mathrm{n}=107,123$ and 125 daily trips [93.4\% of the total number of trips] vs 12,0 and 13 overnight trips [6.6\%] at AMS, KER and CRO respectively).

On average, birds departed to the sea in the early morning at each site, but arrival time back at the colony was more widespread, occurring on average $1.25,3.59$ and $3.04 \mathrm{~h}$ before sunset at AMS, KER and CRO respectively (Table 1, Fig. 2). Duration of daily foraging trips (about 11 to $12 \mathrm{~h}$ ) did not differ significantly among the 3 study sites (Table 1). This duration represented 93, 76 and $73 \%$ of the daytime at AMS, KER and CRO respectively, daytime was $16 \%$ shorter at AMS in October than at KER and CRO in January (13.08 h vs 15.60 and 15.42 h, respectively) (Fig. 2). Birds which made overnight trips departed later in the morning ( $t$-test: $t=2.46, \mathrm{p}=0.016$ at AMS, and $t=2.19$, $\mathrm{p}=0.030$ at $\mathrm{CRO}$ ), and they returned earlier in the afternoon at CRO but not at AMS $(t=5.10, \mathrm{p}<0.001$, and $t=1.87, \mathrm{p}=0.064$, respectively), than those making daily foraging trips (Table 1). Birds engaged in overnight trips generally returned to the colony the day after departure, but 1 female from AMS remained
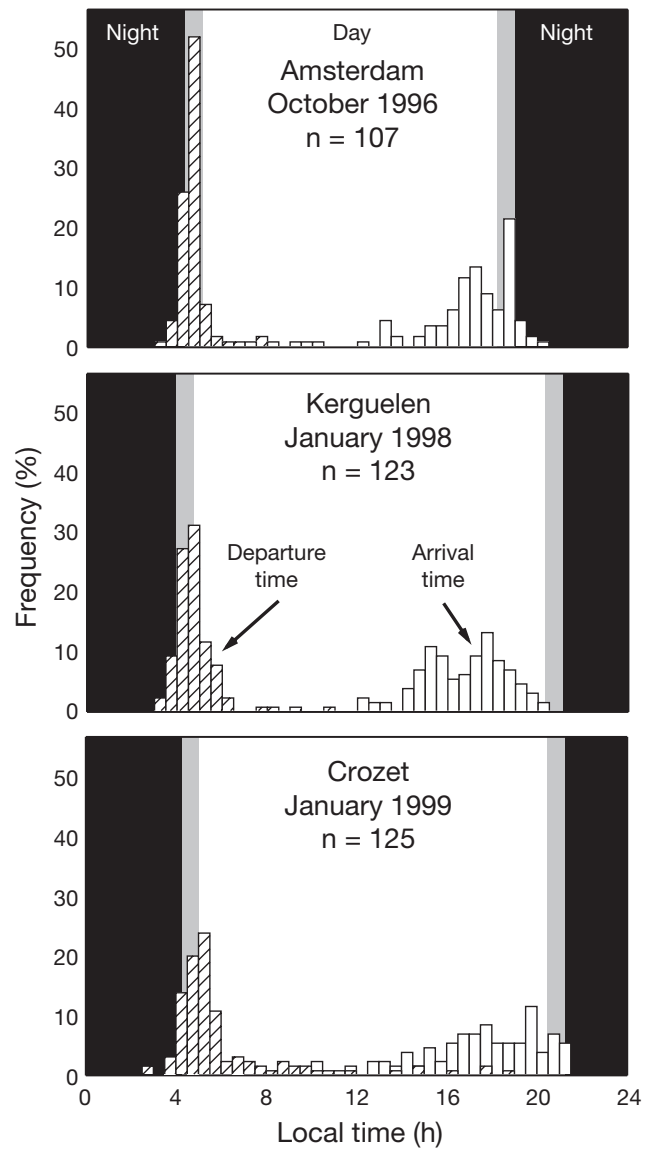

Fig. 2. Eudyptes chrysocome. Frequency distribution of departure and arrival times of daily foraging trips during the brooding period at Amsterdam (AMS), Kerguelen (KER) and Crozet (CRO) Islands

at sea during 2 consecutive nights. Overnight trips were significantly longer $(26 \%)$ at AMS than at CRO (Table 1).

The mean outward and inward travelling times of daily foraging trips were not different at AMS $(t=0.83$, $\mathrm{p}=0.411)$ and at CRO $(t=0.56, \mathrm{p}=0.577)$, and they were identical when comparing the 2 sites (Table 1). Consequently, the estimated foraging ranges on the outward and inward journeys were between $2.8 \pm 3.3$ and $4.1 \pm 3.0 \mathrm{~km}$ at AMS and CRO. At KER, outward travelling time was shorter than inward travelling time $(t=6.02, \mathrm{p}<0.001)$ (Table 1$)$. The estimated foraging ranges were consequently different when calculated at the beginning or the end of the trip $(1.6 \pm 2.2$ and $5.1 \pm 6.3 \mathrm{~km}$ respectively), suggesting that birds moved away while foraging at sea (average distance $=3.6 \pm$ $6.5 \mathrm{~km})$.

The total number of dives, dive frequency and the number of foraging dives per daily trip were different among the study sites, in the order AMS $>$ KER $>$ CRO 
Table 1. Eudyptes chrysocome. Characteristics of foraging trips during the brooding period at Amsterdam (AMS), Kerguelen (KER) and Crozet (CRO) Islands. "Statistics: values in the same horizontal row not sharing a common letter are significantly different (Bonferroni post-hoc comparison tests)

\begin{tabular}{|c|c|c|c|c|c|c|c|c|c|c|c|c|c|c|c|c|c|}
\hline & \multirow{2}{*}{\multicolumn{5}{|c|}{$\begin{array}{c}\text { Amsterdam } \\
\text { Daily trips: } \mathrm{n}=107\end{array}$}} & \multirow{2}{*}{\multicolumn{5}{|c|}{$\begin{array}{c}\text { Kerguelen } \\
\text { Daily trips: } \mathrm{n}=123\end{array}$}} & \multirow{2}{*}{\multicolumn{5}{|c|}{$\begin{array}{c}\text { Crozet } \\
\text { Daily trips: } \mathrm{n}=125\end{array}$}} & \multicolumn{2}{|c|}{ Statistics } \\
\hline & & & & & & & & & & & & & & & & \multirow{2}{*}{$\begin{array}{c}F \\
(\mathrm{df}=2,113)\end{array}$} & \multirow[t]{2}{*}{$\mathrm{p}$} \\
\hline & Mean & $\mathrm{SD}$ & ${ }^{*}$ & Min & Max & Mean & $\mathrm{SD}$ & * & Min & Max & Mean & $\mathrm{SD}$ & ${ }^{*}$ & Min & Max & & \\
\hline Departure time (local time: $\mathrm{h}$ ) & 4.71 & 0.61 & $\mathrm{a}$ & 3.12 & 7.83 & 4.88 & 1.32 & a & 3.11 & 14.53 & 6.13 & 2.95 & $\mathrm{~b}$ & 2.90 & 18.88 & 15.17 & $<0.001$ \\
\hline Returning time (local time: h) & 16.88 & 2.45 & $\mathrm{a}$ & 7.28 & 20.21 & 16.73 & 1.84 & a & 12.18 & 20.48 & 17.36 & 2.87 & $\mathrm{a}$ & 8.67 & 21.30 & 0.94 & 0.392 \\
\hline Foraging trip duration (h) & 12.17 & 2.47 & a & 3.44 & 16.01 & 11.85 & 1.95 & a & 4.77 & 16.04 & 11.23 & 3.51 & $\mathrm{a}$ & 1.08 & 16.64 & 2.37 & 0.098 \\
\hline Total number of dives & 458 & 165 & $\mathrm{a}$ & 108 & 1077 & 349 & 109 & b & 190 & 743 & 299 & 107 & $\mathrm{c}$ & 34 & 646 & 24.05 & $<0.001$ \\
\hline Number of travelling dives & 96 & 73 & a & 13 & 383 & 57 & 73 & b & 1 & 400 & 51 & 67 & $\mathrm{~b}$ & 0 & 472 & 9.81 & $<0.001$ \\
\hline Number of foraging dives & 362 & 129 & $\mathrm{a}$ & 70 & 727 & 292 & 69 & $\mathrm{~b}$ & 172 & 574 & 247 & 76 & $\mathrm{c}$ & 31 & 398 & 19.41 & $<0.001$ \\
\hline Outward travelling time $(\mathrm{h})$ & 0.51 & 0.29 & $\mathrm{a}$ & 0.00 & 1.95 & 0.21 & 0.30 & $\mathrm{~b}$ & 0.00 & 1.60 & 0.41 & 0.45 & $\mathrm{a}$ & 0.00 & 2.37 & 14.05 & $<0.001$ \\
\hline Inward travelling time $(\mathrm{h})$ & 0.56 & 0.40 & $\mathrm{ab}$ & 0.00 & 1.99 & 0.69 & 0.85 & $\mathrm{a}$ & 0.00 & 5.52 & 0.38 & 0.44 & $\mathrm{~b}$ & 0.00 & 2.64 & 6.57 & 0.002 \\
\hline Dive frequency (dives $\mathrm{h}^{-1}$ ) & 37.2 & 9.5 & $\mathrm{a}$ & 21.6 & 71.7 & 29.6 & 8.9 & $\mathrm{~b}$ & 18.7 & 85.8 & 27.1 & 5.9 & $\mathrm{c}$ & 12.7 & 52.5 & 23.66 & $<0.001$ \\
\hline Mean dive depth (m) & 18.7 & 5.5 & $\mathrm{a}$ & 8.4 & 36.3 & 26.3 & 7.9 & $\mathrm{~b}$ & 8.8 & 47.1 & 33.9 & 8.7 & $\mathrm{c}$ & 11.5 & 51.8 & 65.88 & $<0.001$ \\
\hline SD of dive depth (m) & 14.0 & 5.5 & $\mathrm{a}$ & 4.7 & 28.1 & 13.4 & 3.9 & a & 5.0 & 23.6 & 18.0 & 4.4 & $\mathrm{~b}$ & 6.4 & 29.4 & 16.44 & $<0.001$ \\
\hline Vertical travel distance (VTD) (km) & 16.02 & 3.97 & $\mathrm{a}$ & 1.93 & 24.38 & 17.38 & 4.68 & a & 6.19 & 30.96 & 20.06 & 7.47 & $\mathrm{~b}$ & 1.43 & 33.92 & 11.04 & $<0.001$ \\
\hline Total dive time (h) & 7.83 & 1.93 & a & 1.31 & 10.76 & 7.35 & 1.66 & a & 3.07 & 11.26 & 7.22 & 2.42 & $\mathrm{a}$ & 0.75 & 11.88 & 2.77 & 0.067 \\
\hline Total dive time (\% of trip duration) & 63.9 & 8.1 & a & 29.7 & 79.8 & 61.9 & 8.8 & a & 37.7 & 77.9 & 64.2 & 8.5 & $\mathrm{a}$ & 15.8 & 79.1 & 1.74 & 0.181 \\
\hline Total time spent at the bottom (h) & 4.23 & 1.17 & $\mathrm{~b}$ & 0.76 & 6.36 & 4.70 & 1.20 & $\mathrm{~b}$ & 1.95 & 7.72 & 4.09 & 1.43 & a & 0.42 & 6.92 & 4.39 & 0.015 \\
\hline \multirow[t]{3}{*}{ Intra-depth zone (IDZ) dives (\%) } & 33.2 & 8.7 & $\mathrm{a}$ & 15.7 & 67.9 & 58.0 & 12.1 & $\mathrm{~b}$ & 29.8 & 85.9 & 49.4 & 10.4 & c & 10.7 & 76.2 & 93.32 & $<0.001$ \\
\hline & \multicolumn{5}{|c|}{ Overnight trips: $\mathrm{n}=12$} & \multicolumn{5}{|c|}{ Overnight trips: $\mathrm{n}=0$} & \multicolumn{5}{|c|}{ Overnight trips: $\mathrm{n}=13$} & & $p$ \\
\hline & Mean & $\mathrm{SD}$ & & Min & $\operatorname{Max}$ & Mean & $\mathrm{SD}$ & & Min & Max & Mean & $\mathrm{SD}$ & & Min & Max & $(\mathrm{df}=1,17)$ & \\
\hline Departure time (local time: h) & 5.49 & 2.82 & & 4.10 & 14.41 & - & - & & - & - & 8.18 & 5.19 & & 4.25 & 18.83 & 2.07 & 0.168 \\
\hline Returning time (local time: $\mathrm{h}$ ) & 15.43 & 3.33 & & 8.76 & 19.11 & - & - & & - & - & 12.73 & 5.05 & & 3.49 & 20.76 & 2.19 & 0.157 \\
\hline Foraging trip duration (h) & 35.95 & 6.59 & & 24.97 & 52.66 & - & - & & - & - & 28.55 & 4.97 & & 20.95 & 34.99 & 8.67 & 0.009 \\
\hline Total number of dives & 1123 & 262 & & 701 & 1650 & - & - & & - & - & 744 & 161 & & 509 & 1085 & 14.22 & 0.002 \\
\hline Number of travelling dives & 210 & 109 & & 77 & 421 & - & - & & - & - & 226 & 116 & & 71 & 465 & 0.04 & 0.850 \\
\hline Number of foraging dives & 913 & 221 & & 580 & 1254 & - & - & & - & - & 518 & 99 & & 364 & 684 & 21.42 & $<0.001$ \\
\hline Outward travelling time $(\mathrm{h})$ & 0.57 & 0.26 & & 0.21 & 1.14 & - & - & & - & - & 0.58 & 0.57 & & 0.03 & 1.96 & 0.00 & 0.964 \\
\hline Inward travelling time $(\mathrm{h})$ & 0.43 & 0.19 & & 0.14 & 0.81 & - & - & & - & - & 1.04 & 1.84 & & 0.00 & 6.82 & 1.56 & 0.228 \\
\hline Dive frequency (dives $\mathrm{h}^{-1}$ ) & 31.2 & 4.7 & & 24.8 & 43.0 & - & - & & - & - & 26.2 & 3.9 & & 21.2 & 33.0 & 4.92 & 0.041 \\
\hline Mean dive depth (m) & 16.4 & 3.7 & & 11.1 & 23.5 & - & - & & - & - & 27.0 & 5.7 & & 16.0 & 34.2 & 26.56 & $<0.001$ \\
\hline SD of dive depth (m) & 10.7 & 4.3 & & 6.3 & 18.2 & - & - & & - & - & 22.3 & 2.8 & & 17.0 & 26.2 & 44.38 & $<0.001$ \\
\hline Vertical travel distance (VTD) (km) & 35.27 & 4.66 & & 29.17 & 44.97 & - & - & & - & - & 39.50 & 8.83 & & 22.13 & 50.86 & 1.49 & 0.239 \\
\hline Total dive time (h) & 17.72 & 2.61 & & 13.88 & 23.06 & - & - & & - & - & 15.51 & 3.34 & & 10.42 & 20.67 & 4.06 & 0.060 \\
\hline Total dive time (\% of trip duration) & 49.7 & 3.9 & & 43.8 & 55.6 & - & - & & - & - & 54.1 & 4.3 & & 48.9 & 62.9 & 4.06 & 0.062 \\
\hline Total time spent at the bottom (h) & 10.15 & 1.96 & & 7.01 & 13.60 & - & - & & - & - & 9.01 & 2.19 & & 6.08 & 13.55 & 3.08 & 0.097 \\
\hline Intra-depth zone (IDZ) dives (\%) & 37.0 & 7.9 & & 26.8 & 50.0 & - & - & & - & - & 45.2 & 3.4 & & 40.6 & 52.1 & 5.44 & 0.032 \\
\hline
\end{tabular}

(Table 1). However, the proportion of foraging dives was significantly lower at AMS $(79.6 \pm 11.7 \%)$, being identical at KER $(86.1 \pm 12.7 \%)$ and at CRO $(85.0 \pm$ $13.3 \%$ ) (percentages were arcsine transformed, nestedANOVA: $\left.F_{2,113}=8.22, \mathrm{p}<0.001\right)$. When analysing the data sets of randomly selected dives (see 'Materials and methods'), distributions of foraging dives were relatively constant over the course of the daily trips, and they did not differ between the 3 sites (Pearson chi-squared test: $\chi_{38}^{2}=52.29, p=0.06$ ) (Fig. 3). Distributions of travelling dives differed however among sites $\left(\chi_{38}^{2}=126.7, p<0.001\right)$. Travelling dives were symmetrically distributed at the beginning and the end of the daily trips at AMS and CRO. At KER, the distribution of travelling dives was skewed to the right, few travelling dives occurring at the beginning of the trips, while their proportion increased during the second half of the trip (Fig. 3).

\section{Dive parameters}

Among the 62 470, 42971 and 46992 recorded dives, the deepest dives reached 93, 85 and $104 \mathrm{~m}$, and the longest dives lasted 193, 177 and $190 \mathrm{~s}$ at AMS, KER and CRO respectively. The distribution of dive depth and duration was bimodal at each site, with 1 peak at the shallowest and shortest duration $(5 \mathrm{~m}, 10$ to $20 \mathrm{~s}$ at all sites), and 1 peak for deeper and longer dives $(17,30$ and $45 \mathrm{~m}$, and 30 to 120,100 and $120 \mathrm{~s}$ at AMS, KER and CRO respectively) (Fig. 4). Female rockhopper penguins dived at increasing depths in the order AMS, KER and CRO, and, in agreement with those differences, the duration of foraging dives was shorter at AMS, intermediate at KER and longer at CRO (Tables 1 \& 2, Figs. 4 \& 5). At all sites, the deepest and longest dives were generally performed in the middle of the day. 


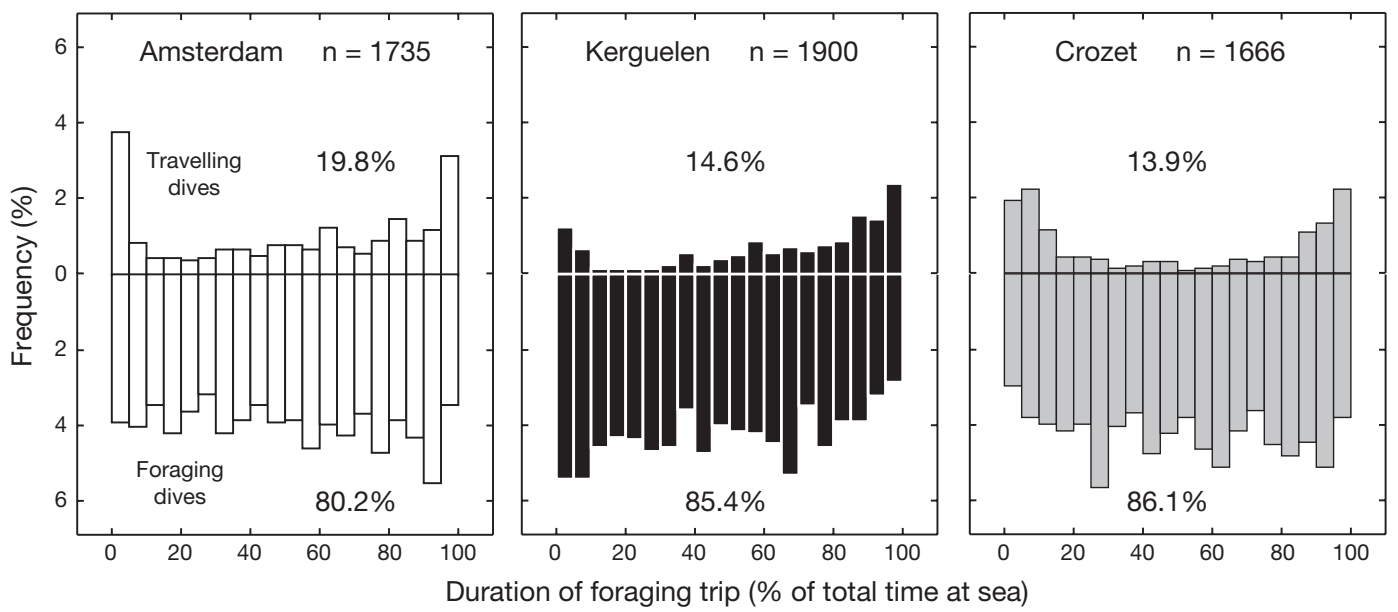

Fig. 3. Eudyptes chrysocome. Frequency distribution of travelling and foraging dives from randomly selected data sets (see 'Materials and methods') over the course of daily foraging trips at Amsterdam (AMS), Kerguelen (KER) and Crozet (CRO) Islands
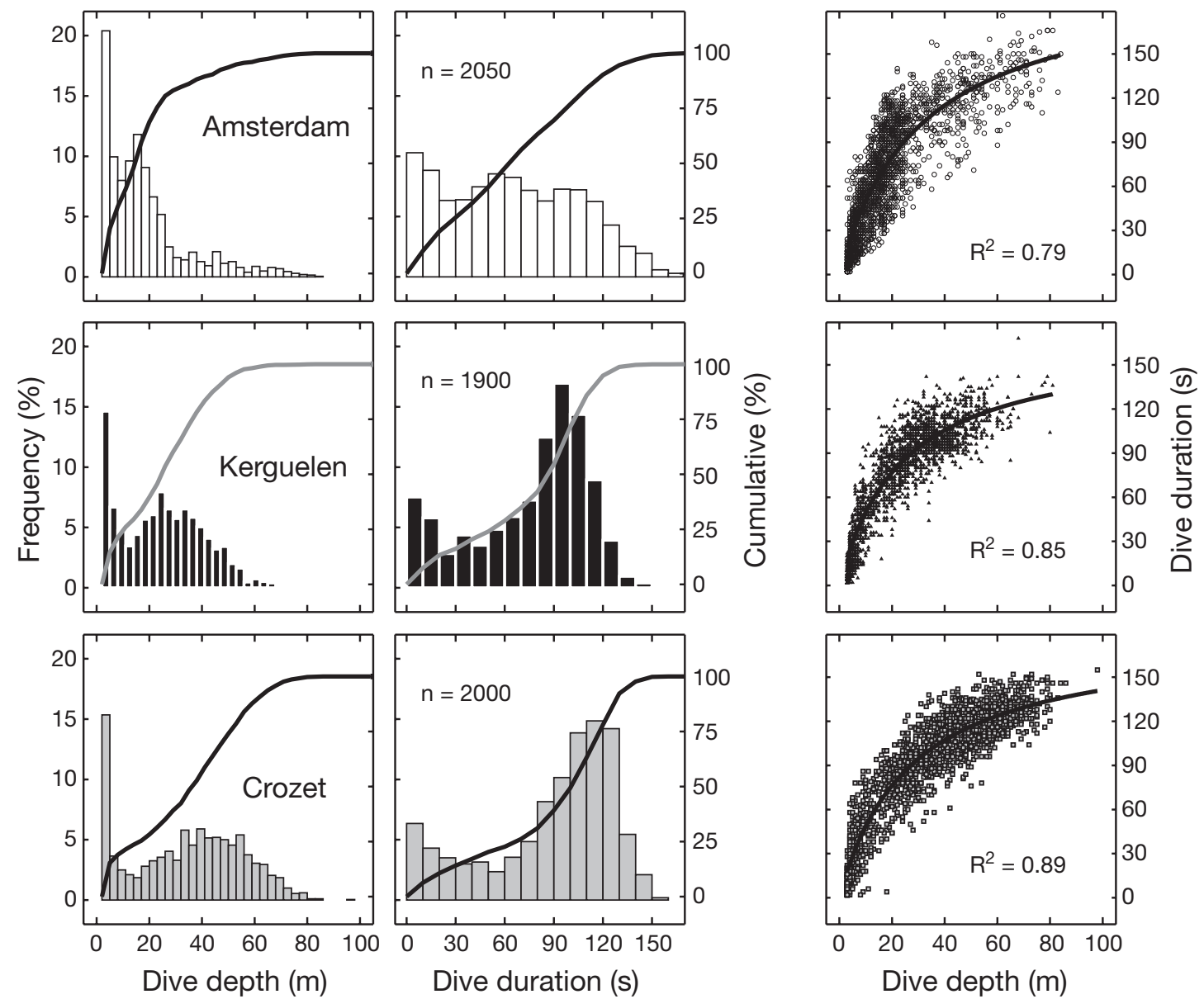

Fig. 4. Eudyptes chrysocome. Frequency distribution of dive depth and dive duration, and relationship between dive duration and dive depth for dives from randomly selected data sets (see 'Materials and methods') at Amsterdam (AMS), Kerguelen (KER) and Crozet (CRO) Islands. Dive duration is positively related to dive depth, the relationship being well fitted by the hyperbole: duration $=(a \times$ depth $):(b+$ depth $)$, with $a=204.61,168.37$ and 179.39 , and $b=31.10,23.83$ and 26.97 at AMS, KER and 
Table 2. Eudyptes chrysocome. Characteristics of foraging dives (>5 m) from the randomly selected data sets (see 'Materials and methods') during the brooding period at Amsterdam (AMS), Kerguelen (KER) and Crozet (CRO) Islands. ${ }^{*}$ Statistics (ANOVA: hypothesis test of site effect with 'bird nested into site' as the error term): values in the same horizontal row not sharing a common letter are significantly different (Bonferroni post-hoc comparison tests)

\begin{tabular}{|c|c|c|c|c|c|c|c|c|}
\hline & $\begin{array}{l}\text { Amsterd } \\
\mathrm{n}=1632 \\
\text { Mean } \pm \mathrm{SD}\end{array}$ & * & $\begin{array}{c}\text { Kerguel } \\
\mathrm{n}=1622 \\
\text { Mean } \pm \mathrm{SD}\end{array}$ & * & $\begin{array}{c}\quad \text { Crozet } \\
\mathrm{n}=1693 \\
\text { Mean } \pm \mathrm{SD}\end{array}$ & ${ }^{*}$ & $\begin{array}{c}F \text { ratio } \\
\mathrm{df}=2,116\end{array}$ & $\mathrm{p}$ \\
\hline Dive depth (m) & $22.5 \pm 15.7$ & $\mathrm{a}$ & $29.1 \pm 14.1$ & $\mathrm{~b}$ & $40.4 \pm 17.6$ & $\mathrm{C}$ & 102.60 & $<0.001$ \\
\hline Dive duration (s) & $78.4 \pm 34.8$ & $\mathrm{a}$ & $87.4 \pm 26.2$ & $\mathrm{~b}$ & $101.8 \pm 27.0$ & $\mathrm{C}$ & 47.86 & $<0.001$ \\
\hline Descent rate $\left(\mathrm{m} \mathrm{s}^{-1}\right)$ & $1.13 \pm 0.47$ & $\mathrm{a}$ & $1.59 \pm 0.50$ & $\mathrm{~b}$ & $1.71 \pm 0.64$ & $\mathrm{C}$ & 180.25 & $<0.001$ \\
\hline Ascent rate $\left(\mathrm{m} \mathrm{s}^{-1}\right)$ & $0.93 \pm 0.45$ & $\mathrm{a}$ & $1.27 \pm 0.50$ & $\mathrm{~b}$ & $1.25 \pm 0.50$ & $\mathrm{~b}$ & 50.06 & $<0.001$ \\
\hline Bottom time (s) & $41.8 \pm 20.8$ & $\mathrm{a}$ & $54.7 \pm 20.8$ & $\mathrm{~b}$ & $57.4 \pm 19.1$ & $\mathrm{C}$ & 56.24 & $<0.001$ \\
\hline Post-dive interval (s) ${ }^{\mathrm{a}}$ & $25.2 \pm 15.1$ & $\mathrm{a}$ & $33.3 \pm 15.3$ & $\mathrm{~b}$ & $36.0 \pm 17.5$ & $\mathrm{C}$ & 36.42 & $<0.001$ \\
\hline Between-bottom time $(\mathrm{s})^{\mathrm{a}}$ & $60.6 \pm 28.3$ & $\mathrm{a}$ & $65.5 \pm 22.2$ & $\mathrm{~b}$ & $80.1 \pm 26.8$ & $\mathrm{C}$ & 43.56 & $<0.001$ \\
\hline Dive cycle duration $(\mathrm{s})^{\mathrm{a}}$ & $103.5 \pm 41.4$ & $\mathrm{a}$ & $121.0 \pm 33.1$ & $\mathrm{~b}$ & $138.4 \pm 33.5$ & $\mathrm{C}$ & 60.36 & $<0.001$ \\
\hline Depth-activity index $\left(\mathrm{m} \mathrm{s}^{-1}\right)$ & $0.36 \pm 0.20$ & $\mathrm{a}$ & $0.43 \pm 0.15$ & $\mathrm{~b}$ & $0.54 \pm 0.20$ & C & 92.54 & $<0.001$ \\
\hline Depth-wiggles (n) & $2.4 \pm 2.0$ & $\mathrm{a}$ & $6.5 \pm 4.2$ & $\mathrm{~b}$ & $5.9 \pm 3.4$ & $\mathrm{C}$ & 153.36 & $<0.001$ \\
\hline Diving efficiency ${ }^{\mathrm{a}}$ & $0.40 \pm 0.13$ & $\mathrm{a}$ & $0.45 \pm 0.12$ & $\mathrm{~b}$ & $0.42 \pm 0.11$ & $\mathrm{C}$ & 24.58 & $<0.001$ \\
\hline
\end{tabular}

Of the dives randomly selected, only $25(1.2 \%)$, $7(0.4 \%)$ and $35(1.7 \%)$ occurred during nighttime at AMS, KER and CRO respectively. Diving depth of night dives was identical at the 3 sites (ANOVA: $F_{2,64}=$ 1.15, $\mathrm{p}=0.323)$. They occurred at much shallower depths $(6.9 \pm 4.9 \mathrm{~m}, \mathrm{n}=67)$ than during daytime, most of them being $\leq 15 \mathrm{~m}$. Consequently, birds performing overnight trips (that included 1 to 2 nights at sea) had lower mean dive depths than those performing daily foraging trips (Table 1).
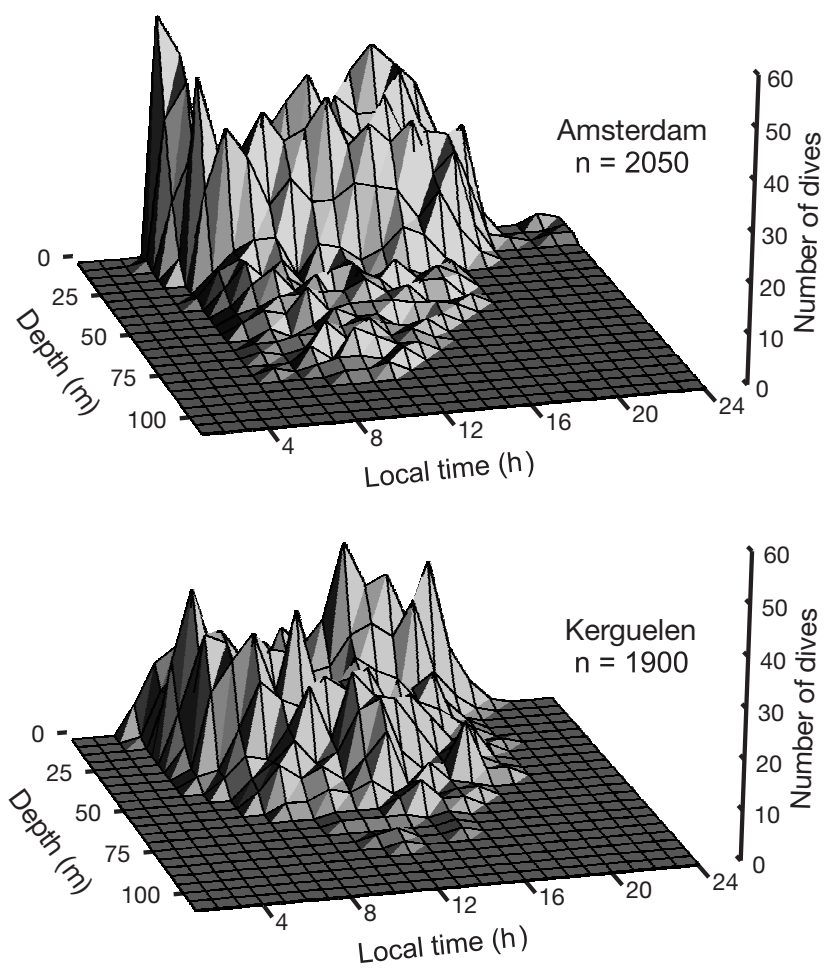

The distribution of post-dive intervals (PDI) was unimodal at 24, 33 and $33 \mathrm{~s}$ at AMS, KER and CRO respectively (Fig. 6). Excluding PDI > 180 s, PDI was positively and linearly related to the preceding dive duration (DD) (Fig. 6). An analysis of covariance showed that slopes were identical (ANCOVA: $F_{2,47}=1.57, \mathrm{p}=0.221, \mathrm{n}=$ $48)$, but that intercepts were different $\left(F_{2,47}=4.32, \mathrm{p}=\right.$ 0.019). Due to a lower intercept, PDI were shorter at AMS, but they were identical at both KER and CRO. PDI were generally shorter than the preceding dives,

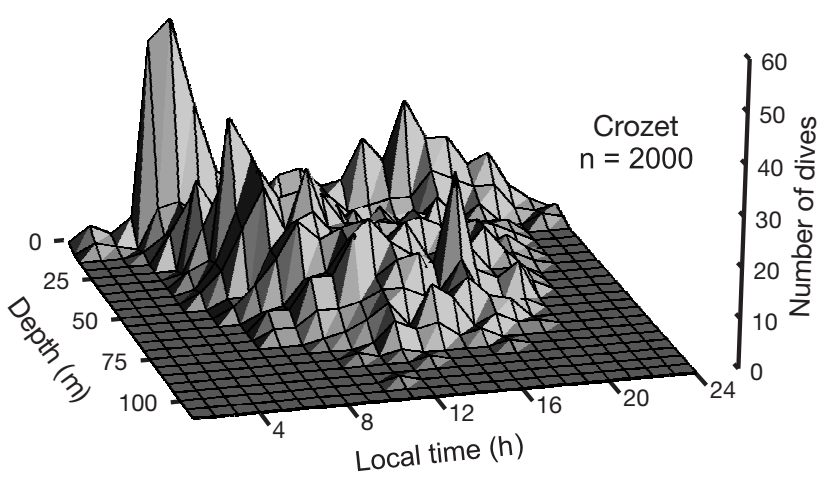

Fig. 5. Eudyptes chrysocome. Distribution of number of dives from randomly selected data sets (see 'Materials and methods') in relation to time of day and dive depth at Amsterdam (AMS), Kerguelen (KER) and Crozet (CRO) Islands 

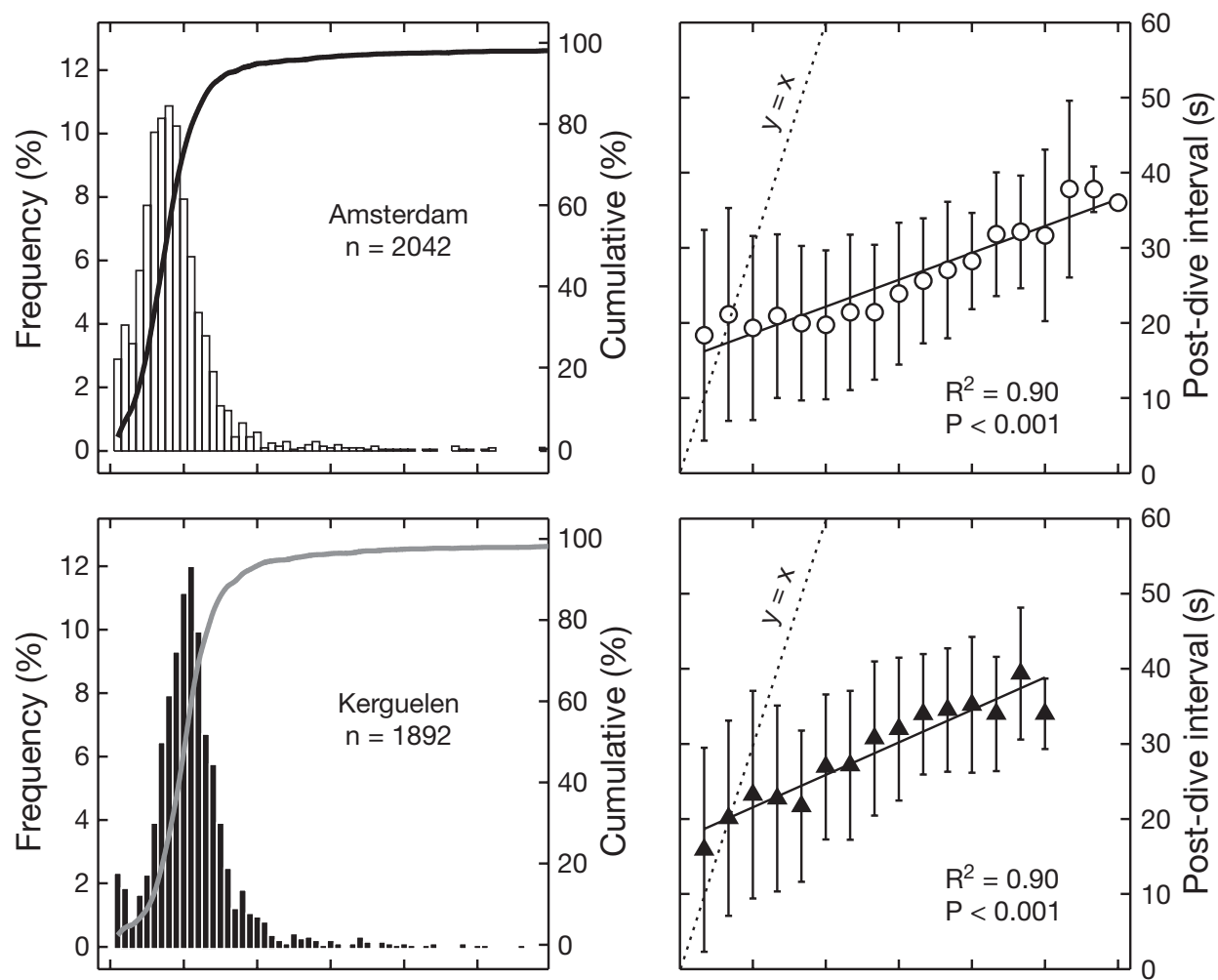

Fig. 6. Eudyptes chrysocome. Frequency distribution of postdive interval (PDI), and relationship between PDI and dive duration (DD) for dives (PDI > $180 \mathrm{~s})$ from randomly selected data sets (see 'Materials and methods') at Amsterdam (AMS), Kerguelen (KER) and Crozet (CRO) Islands. PDI was positively and linearly related to preceding dive duration with slopes $=0.12,0.14$ and 0.13 , and intercepts $=15.02,17.23$ and 19.17 at AMS, KER, and CRO respectively
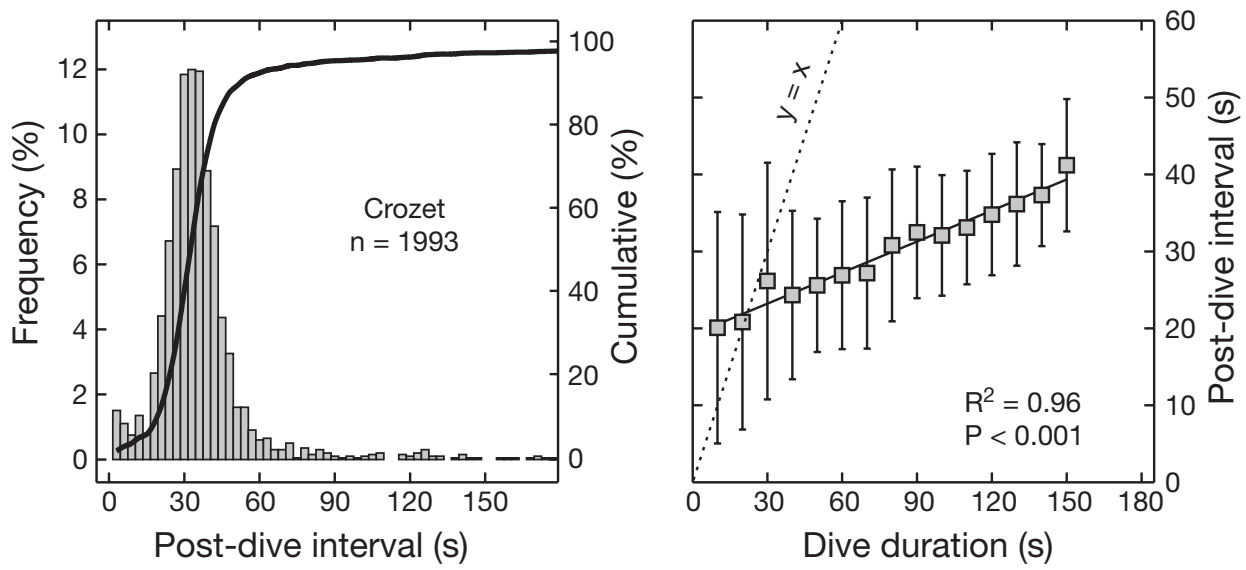

the ratio: $\mathrm{PDI} / \mathrm{DD} \times 100$ averaging 53.3, 62.6 and $56.4 \%$ at AMS, KER and CRO respectively. The ratio decreased as dive duration increased, being $\geq 100 \%$ for $\mathrm{DD} \leq 20 \mathrm{~s}$ and equal to $22.0,25.5$, and $25.8 \%$ for DD = $150 \mathrm{~s}$ at AMS, KER and CRO respectively.

Bottom-time distribution of selected dives was unimodal at 50, 65 and $65 \mathrm{~s}$ at AMS, KER and CRO respectively, bottom time of foraging dives increasing in the order AMS, KER and CRO (Table 2). Diving-efficiency distribution of selected dives was also unimodal at 0.45 , 0.55 and 0.45 at AMS, KER and CRO respectively, diving efficiency of foraging dives being lower at AMS, intermediate at CRO, and higher at KER (Table 2). The mean maximum diving efficiency occurred during dives that reached a maximum depth of 15 to 35,20 to 55 and 20 to $50 \mathrm{~m}$ at AMS, KER and CRO respectively (Fig. 7). Bird activity during bottom time of foraging dives was different at the 3 study sites. Both the number of depth wiggles and the depth-activity indexes were lower at AMS than at KER and CRO, the number of depth wiggles being higher, but the depth-activity lower, at KER than at CRO (Table 2, Fig. 7). The mean vertical distance swum up or down by the birds per wiggle during $\mathrm{W}$-shaped dives differed among the 3 sites, averaging $4.47 \pm 2.60$ ( $\mathrm{n}=$ $734), 3.91 \pm 1.76(\mathrm{n}=1354)$ and $5.68 \pm 2.91 \mathrm{~m}(\mathrm{n}=1466)$ at AMS, KER and CRO respectively (nested-ANOVA: $\left.F_{2,116}=57.18, \mathrm{p}<0.001\right)$. The distance was positively and linearly related to depth (data not shown). 

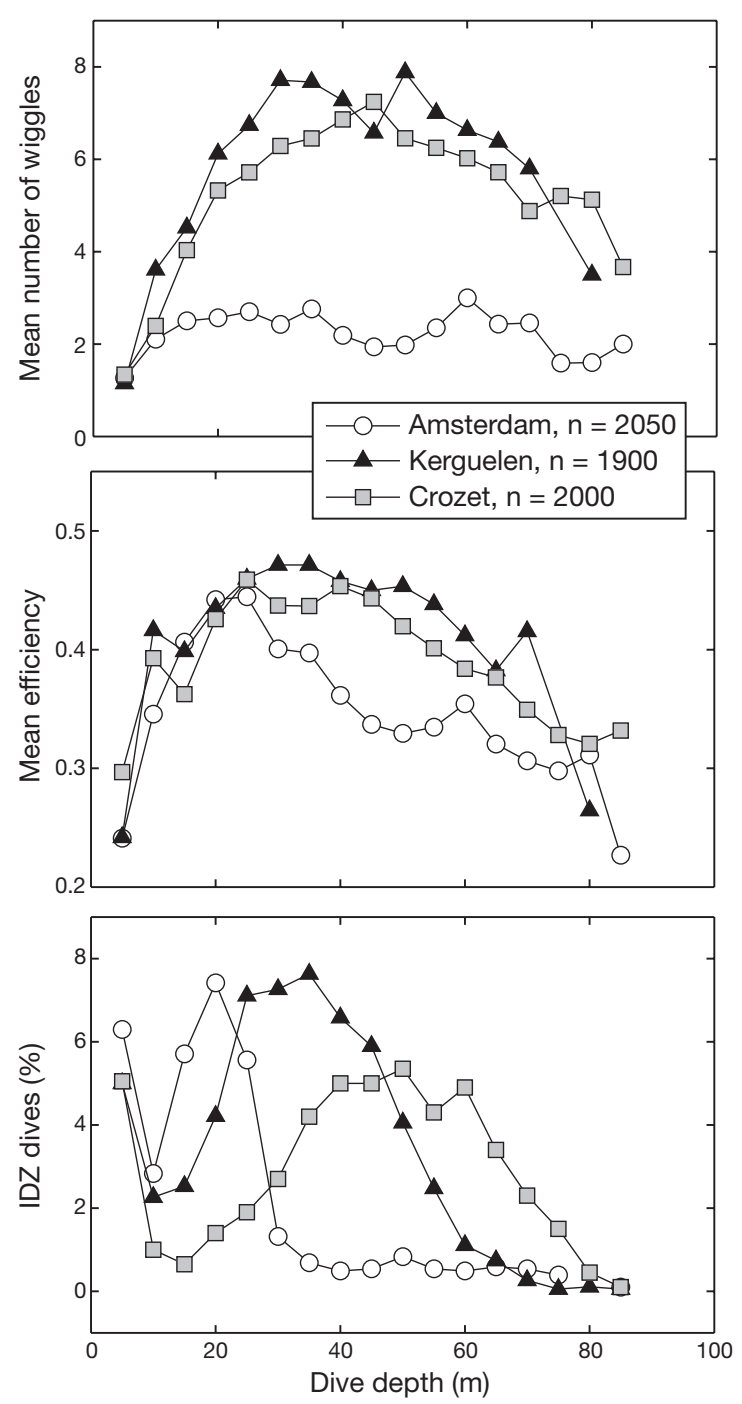

Fig. 7. Eudyptes chrysocome. Number of wiggles, efficiency and proportion of intra-depth zone (IDZ) dives in relation to dive depth for dives from randomly selected data sets (see 'Materials and methods') at Amsterdam (AMS), Kerguelen (KER) and Crozet (CRO) Islands

The proportion of intra-depth zone (IDZ) dives during daily trips varied greatly among localities, birds performing less IDZ dives at AMS than at KER and $\mathrm{CRO}$, the highest values being found at KER (Table 1). IDZ dives peaked at 15 to 25,25 to 45 and 40 to $60 \mathrm{~m}$ at AMS, KER and CRO respectively (Fig. 7). Interestingly, IDZ dives at AMS and KER occurred at dive depths for which diving efficiency was at a maximum, while at CRO they occurred at depths deeper than those for which the highest diving efficiency was found (Fig. 7).

Descent rate was higher than ascent rate at all the study sites (paired $t$-test: all $t>4.5$, all $\mathrm{p}<0.001$ ) (Table 2). Descent and ascent rates were lower at
AMS than at KER and CRO, a difference resulting partly from shallower dive depths at AMS. At KER, the mean descent rate was slower than at CRO (Table 2). Both rates were positively and linearly related to dive depth. An analysis of covariance indicated that the effect of the different slopes (ANCOVA: $F_{1,30}=27.88, \mathrm{p}<0.001$ ) and the effect of the different intercept $\left(F_{1,30}=23.59, \mathrm{p}<0.001\right)$ cancelled each other out at the 2 sites. When compared to birds from KER, those from CRO descended more quickly in the water column for shallower depths but more slowly for deeper depths (Fig. 8). When considering the ascent rates at KER and $\mathrm{CRO}$, the higher slope at $\operatorname{KER}\left(F_{1,30}=61.39, \mathrm{p}<0.001\right)$ compensated for the lower intercept $\left(F_{1,30}=14.99, \mathrm{p}<0.001\right)$, in a way that birds from KER ascended more quickly than those from CRO (Table 2, Fig. 8).
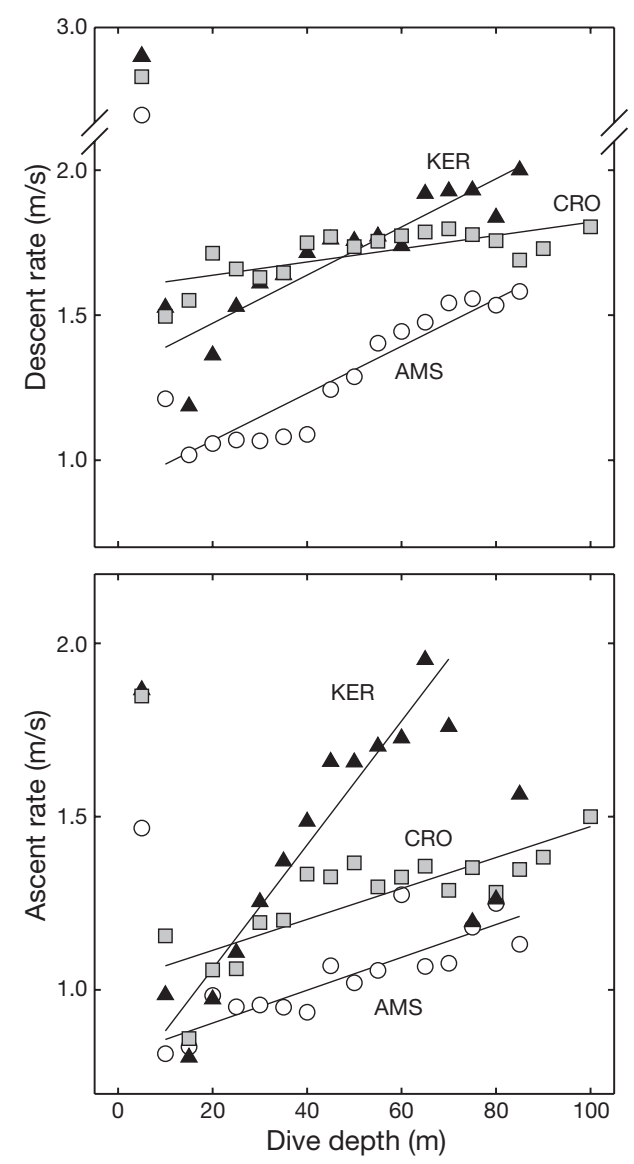

Fig. 8. Eudyptes chrysocome. Descent and ascent rates in relation to dive depth for dives from randomly selected data sets (see 'Materials and methods') at Amsterdam (AMS), Kerguelen (KER) and Crozet (CRO) Islands. Both rates were positively and linearly related to dive depth with slopes $=8.14 \times 10^{-3} / 4.74 \times 10^{-3}$, $9.59 \times 10^{-3} / 17.88 \times 10^{-3}$ and $2.28 \times 10^{-3} / 4.47 \times 10^{-3}$, and intercepts $=0.90 / 0.81,1.27 / 0.70,1.59 / 1.02$ for descent/ascent rates at AMS, KER and CRO respectively (all $\mathrm{R}^{2}>0.5$, all $\mathrm{p}<0.001$ ) 
Table 3. Component loadings of 22 variables from daily foraging trips on the first 3 principal components, which collectively explained $65 \%$ of the total variance in the data. Parameters accounting for most of the variation in each principal component are shown in bold

\begin{tabular}{|lrrr|}
\hline Variable & PC1 & PC2 & PC3 \\
& $30.4 \%$ & $19.8 \%$ & $14.5 \%$ \\
\hline 1 Foraging trip duration & 0.311 & $\mathbf{0 . 7 2 7}$ & 0.131 \\
2 Number of foraging dives & -0.130 & $\mathbf{0 . 9 3 7}$ & -0.066 \\
3 Outward travelling time & -0.175 & 0.115 & $\mathbf{0 . 4 1 3}$ \\
4 Inward travelling time & -0.083 & -0.104 & $-\mathbf{0 . 1 6 6}$ \\
5 Dive frequency & -0.460 & $\mathbf{0 . 6 1 5}$ & -0.234 \\
6 Mean dive depth & $\mathbf{0 . 7 7 1}$ & -0.368 & 0.446 \\
7 SD of dive depth & 0.191 & -0.146 & $\mathbf{0 . 8 5 3}$ \\
8 Mean dive duration & $\mathbf{0 . 8 1 4}$ & -0.288 & 0.365 \\
9 SD of dive duration & -0.413 & 0.286 & $\mathbf{0 . 6 1 7}$ \\
10 Mean bottom time & $\mathbf{0 . 9 1 0}$ & -0.153 & -0.035 \\
11 SD of bottom time & -0.105 & $\mathbf{0 . 3 9 4}$ & 0.208 \\
12 VTD & $\mathbf{0 . 7 1 7}$ & 0.443 & 0.373 \\
13 Total dive time (h) & 0.463 & $\mathbf{0 . 8 3 9}$ & 0.169 \\
14 Total dive time (\%) & 0.415 & $\mathbf{0 . 4 6 0}$ & 0.111 \\
15 Total time spent at the bottom & 0.553 & $\mathbf{0 . 8 0 8}$ & -0.077 \\
16 Mean depth-activity index & $\mathbf{0 . 6 1 2}$ & -0.259 & 0.318 \\
17 SD of depth-activity index & -0.136 & 0.057 & $\mathbf{0 . 7 6 5}$ \\
18 Mean depth wiggles & $\mathbf{0 . 8 3 6}$ & -0.103 & -0.339 \\
19 SD of depth wiggles & $\mathbf{0 . 7 1 5}$ & -0.020 & -0.289 \\
20 Mean diving efficiency & $\mathbf{0 . 5 6 9}$ & 0.339 & -0.457 \\
21 SD of diving efficiency & $\mathbf{- 0 . 5 0 2}$ & 0.285 & -0.044 \\
22 IDZ dives (\%) & $\mathbf{0 . 7 9 3}$ & -0.117 & -0.386 \\
\hline & & & \\
\hline
\end{tabular}

\section{Foraging strategies}

We used a principal component analysis (PCA) on 22 variables calculated for each of the 355 daily foraging trips to characterise and compare foraging strategies at the 3 sites (Table 3). Most of the variables were calculated for foraging dives, excluding travelling dives. The PCA reduced the original variables to 3 principal components (PC1, PC2 and PC3) that accounted for $65 \%$ of the total variance in the data. PC1 was primarily associated with 10 variables including dive depth, dive duration, bottom time, number of depth wiggles, depth-activity index and diving efficiency. Foraging trips having a high value for PC1 were thus characterised by longer, deeper, and more active and efficient foraging dives that were often performed at similar dive depths. PC2 was associated with 7 variables including trip duration, number of dives, dive frequency and total dive time, and PC3 with 5 variables, including travelling times and the SD of various parameters (Table 3). Therefore, the 3 principal components were mostly associated with diving patterns (PC1), foraging effort (PC2) and variation in diving behaviour (PC3).

The distribution of PC values among the 3 axes distinguished 3 groups of daily foraging trips corresponding to the 3 study sites (Fig. 9). In addition, a discriminant function analysis performed on the same 22 variables classified correctly 100, 93 and $96 \%$ of the trips performed at AMS, KER and CRO respectively (data not shown). PC1 value was lower at AMS, but it was identical at KER and CRO $(-2.71 \pm 1.32,1.16 \pm 1.95$ and $1.18 \pm 2.17$ respectively; ANOVA: $F_{2,352}=160.9$, $\mathrm{p}<0.001)$. PC2 value was different at all the study sites $\left(F_{2,352}=33.9, \mathrm{p}<0.001\right)$, averaging $1.13 \pm 2.23,-0.01 \pm$ 1.74 and $-0.95 \pm 1.80$ at AMS, KER and CRO respectively. Finally, PC3 value was lower at KER, but similar at AMS and CRO $(0.76 \pm 1.59,-1.52 \pm 1.24$ and $0.85 \pm$ 1.38 at AMS, KER and CRO respectively; $F_{2,352}=111.5$, $\mathrm{p}<0.001)$. Foraging trips from AMS were segregated from those performed at KER and CRO on PC1, and foraging trips from KER were segregated from those performed at AMS and CRO on PC3 (Fig. 9).
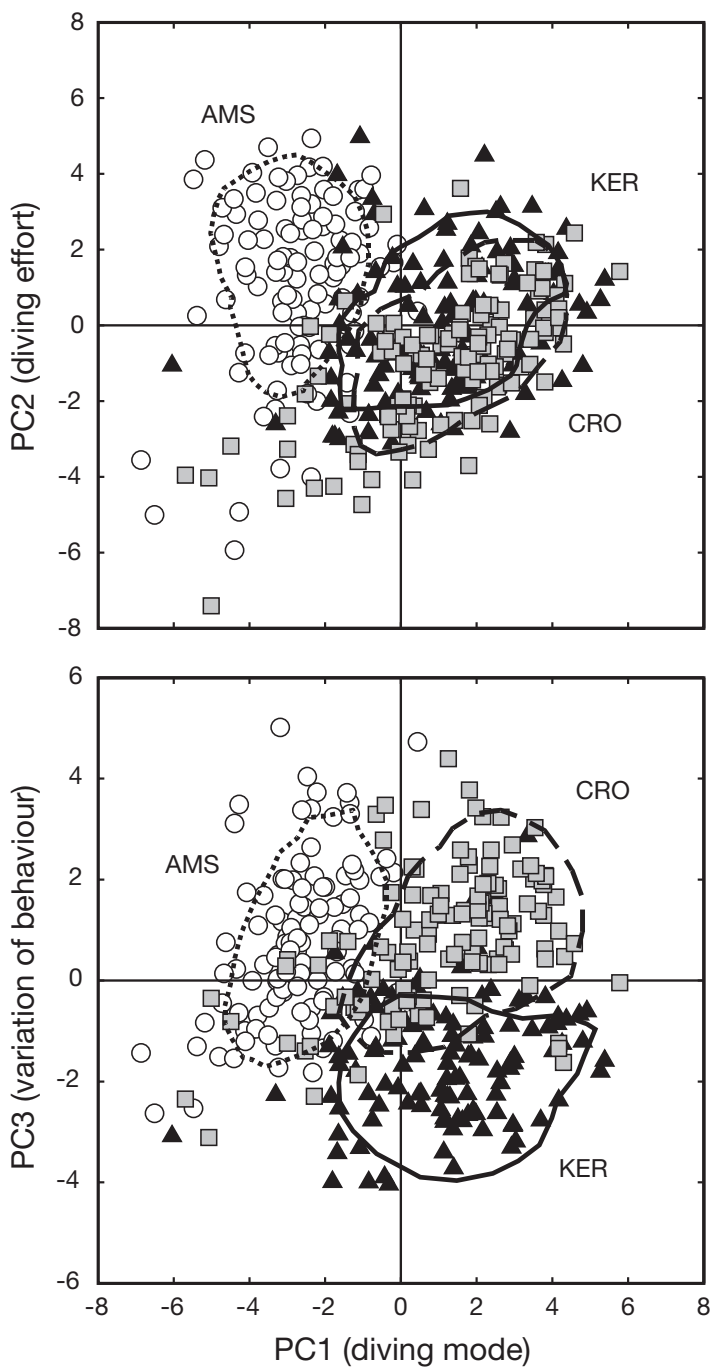

Fig. 9. Component loadings of 22 variables from daily foraging trips on first 3 principal components (PC1, $\mathrm{PC} 2$ and $\mathrm{PC} 3$, see Table 4). PC1 was mainly related to diving mode, PC2 to foraging effort and PC3 to variation in diving behaviour (see 'Results') 
Table 4. Eudyptes chrysocome. Measurements (mm) of female penguins breeding at Amsterdam (AMS), Kerguelen (KER) and Crozet (CRO) Islands. Values are means $\pm \mathrm{SD}$ with ranges in parentheses. Values in the same horizontal row not sharing a common superscript letter are significantly different (Bonferroni post-hoc tests)

\begin{tabular}{|c|c|c|c|c|c|}
\hline \multirow[t]{2}{*}{ Parameter } & \multirow{2}{*}{$\begin{array}{c}\text { Amsterdam } \\
\text { ssp. moseleyi } \\
\mathrm{n}=46\end{array}$} & \multirow{2}{*}{$\begin{array}{l}\text { Kerguelen } \\
\text { ssp. filholi } \\
\mathrm{n}=57\end{array}$} & \multirow{2}{*}{$\begin{array}{l}\text { Crozet } \\
\text { ssp. filholi } \\
\mathrm{n}=59\end{array}$} & \multicolumn{2}{|c|}{ Statistics } \\
\hline & & & & $\begin{array}{c}F \\
(\mathrm{df}=2,159)\end{array}$ & $p$ \\
\hline Flipper length & $\begin{array}{r}152.5 \pm 4.7^{\mathrm{a}} \\
(138-161)\end{array}$ & $\begin{array}{r}147.9 \pm 4.0^{\mathrm{b}} \\
(138-156)\end{array}$ & $\begin{array}{r}147.8 \pm 4.2^{\mathrm{b}} \\
(139-158)\end{array}$ & 19.48 & $<0.001$ \\
\hline Bill length & $\begin{array}{l}43.2 \pm 1.5^{\mathrm{a}} \\
(40.1-47.0)\end{array}$ & $\begin{array}{l}40.0 \pm 1.7^{b} \\
(36.9-43.5)\end{array}$ & $\begin{array}{l}39.9 \pm 1.7^{b} \\
(36.2-43.5)\end{array}$ & 65.21 & $<0.001$ \\
\hline
\end{tabular}

$1091 \pm 127 \mathrm{~g}$ at 20 to $25 \mathrm{~d}$ of age at AMS, KER and CRO respectively; $F_{2,108}=$ 12.14, p $<0.001$ ) (Fig. 11). The same difference in growth rate between sites was found in the foraging colonies $(32.1 \pm 10.6,41.1 \pm 6.0$ and $37.8 \pm 8.9 \mathrm{~g}$ $\mathrm{d}^{-1}$ at AMS, KER and CRO respectively; $\left.F_{2,110}=9.67, \mathrm{p}<0.001\right)$. Chicks from the foraging colonies in which most females were sampled were, on average, lighter than chicks from the control colonies at each study site (ANOVA: all $F>7.2$, all $\mathrm{p}<0.01, \mathrm{n}=64,133,111$ at AMS, KER and CRO respectively), Female measurements, food mass and chick growth

Our data confirmed that the subtropical subspecies moseleyi is larger than the subantarctic subspecies filholi (Cooper et al. 1990, Williams 1995). Flipper and bill lengths from female rockhopper penguins were longer at AMS than at KER and CRO (Table 4). Female body mass decreased linearly during the brooding period at the 3 study sites (Fig. 10). The slopes, i.e. the daily body mass losses, were not statistically different $\left(-15.2 \pm 20.5,-26.7 \pm 21.4\right.$ and $-21.8 \pm 23.7 \mathrm{~g} \mathrm{~d}^{-1}$ at AMS, KER and CRO respectively; ANCOVA: $F_{2,111}=$ 2.58, $\mathrm{p}=0.081$ ), but the intercept, i.e. the body mass at hatching, was lower at AMS than at KER and CRO $(2243 \pm 225,2688 \pm 285$ and $2665 \pm 282 \mathrm{~g}$ at AMS, KER and CRO respectively; $F_{2,111}=28.8, \mathrm{p}<0.001$ ). Consequently, at a given chick age, females from AMS were lighter than those from KER and CRO (Fig. 10).

The mass of food brought ashore by females to feed their chicks was lower at AMS (107.5 $\pm 47.5 \mathrm{~g})$, intermediate at CRO $(150.6 \pm 50.5 \mathrm{~g})$ and higher at KER $(214.8 \pm 62.3 \mathrm{~g})$ (ANOVA: $\left.F_{2,94}=34.66, \mathrm{p}<0.001\right)$. However, food sampling was performed on females having chicks of different age $(9.2 \pm 8.0,16.7 \pm 6.5$ and $10.9 \pm 4.6 \mathrm{~d}$ at AMS, KER and CRO respectively), and food load increased linearly with chick age at KER and CRO, but not at AMS (ANOVA: $F_{2,84}=11.6$, p < 0.001) (Fig. 11). An analysis of covariance indicated that the slopes were not statistically different (ANCOVA: $\left.F_{1,62}=0.89, \mathrm{p}=0.350\right)$, but that the intercept was higher at KER than at $\operatorname{CRO}\left(F_{1,62}=5.72, \mathrm{p}=0.020\right)$. Independent of chick age, females brought more food to their chicks at KER than at $\mathrm{CRO}$; removing the chick-age effect reduced the difference from 64.2 to $33.7 \mathrm{~g}$ (adjusted means: $201.7 \pm 52.1$ and $168.0 \pm 53.0 \mathrm{~g}$ at KER and CRO respectively).

Chick growth rate in the control colony was lower at AMS than at KER and CRO $(38.0 \pm 7.1,46.5 \pm 6.7$ and $43.6 \pm 6.7 \mathrm{~g} \mathrm{~d}^{-1}$, respectively; $\left.F_{2,192}=19.91, \mathrm{p}<0.001\right)$ resulting in lower chick body mass at the end of the brooding period at AMS $(923 \pm 192,1097 \pm 175$ and the growth rates being 5.9, 5.4 and $5.6 \mathrm{~g} \mathrm{~d}^{-1}$ lower in the foraging than in the control colonies at AMS, KER and $\mathrm{CRO}$, respectively.

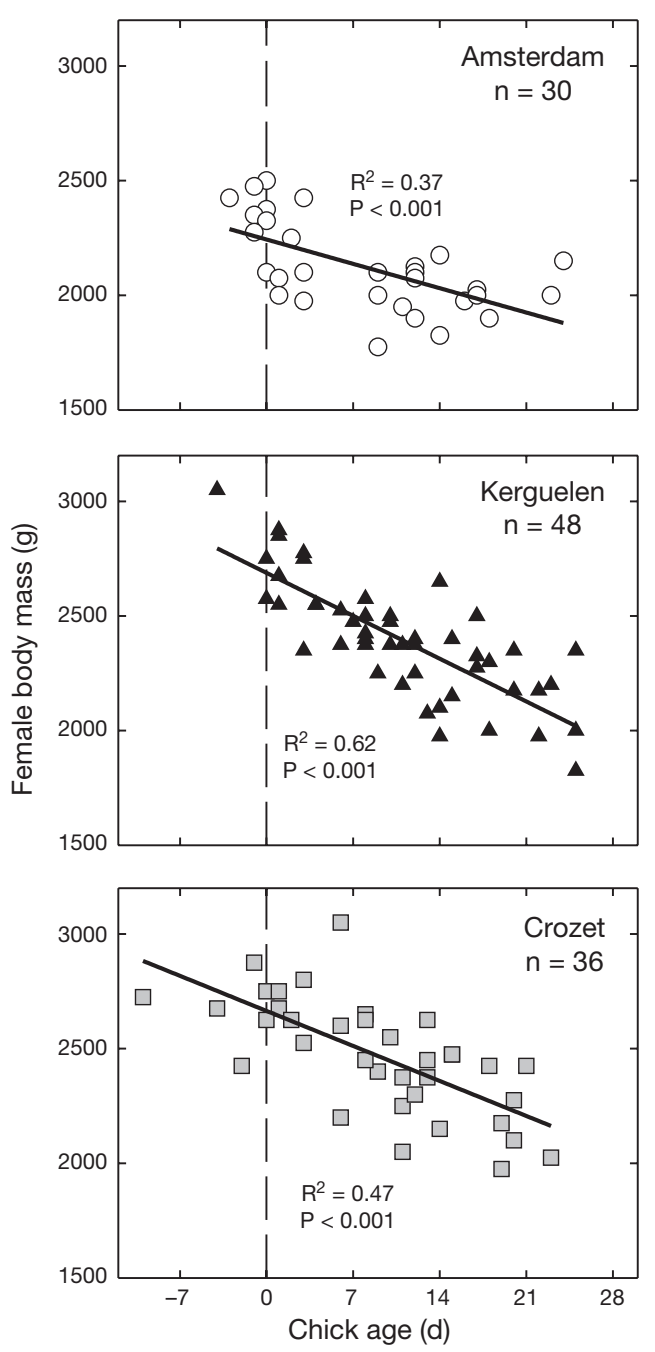

Fig. 10. Eudyptes chrysocome. Body mass of female penguins in relation to age of chicks during brooding period at Amsterdam (AMS), Kerguelen (KER) and Crozet (CRO) Islands 


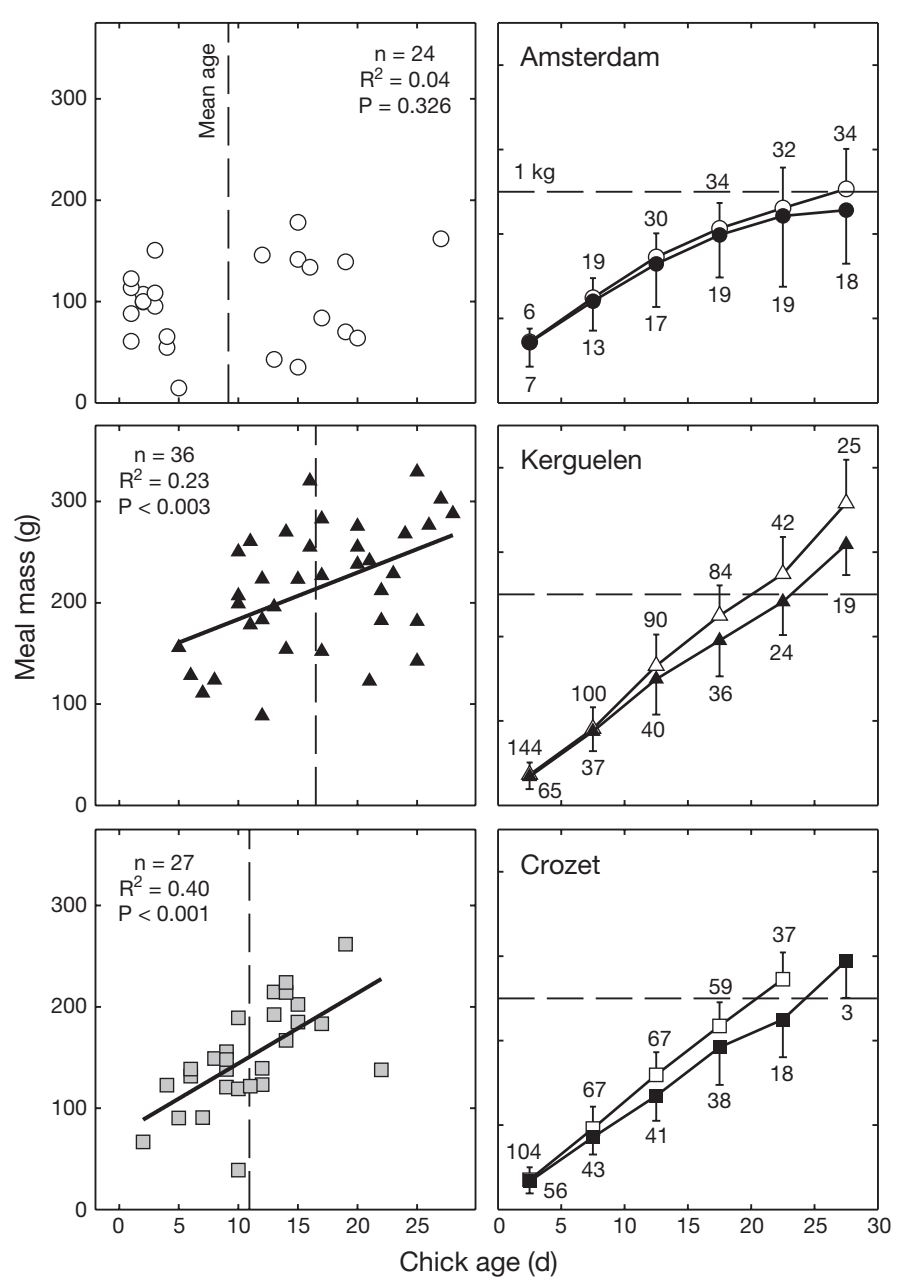

Fig. 11. Eudyptes chrysocome. Food mass and chick body mass in foraging (black symbols) and control (white symbols) colonies in relation to age of chicks during brooding period at Amsterdam (AMS), Kerguelen (KER) and Crozet (CRO) Islands

\section{Foraging effort and temporal changes in foraging characteristics and food mass}

When considering daily foraging trips only, their duration was identical at the 3 sites (see above), as were the absolute ( 7 to $8 \mathrm{~h}$ ) and relative ( 62 to $64 \%$ ) total dive times (sum of durations of dives $\geq 3 \mathrm{~m}$ ) (Table 1). The total number of dives, number of foraging dives and dive frequency were higher at AMS, intermediate at KER and lower at CRO. However, the VTD, which integrates both the number and the depth of dives, was identical at AMS and KER, and was higher at CRO (16 to $17 \mathrm{vs} 20 \mathrm{~km}$ respectively) (Table 1).

At AMS, the number of dives per daily foraging trip increased $\left(\mathrm{R}^{2}=0.23, \mathrm{p}<0.001\right)$, and the mean dive depth decreased $\left(\mathrm{R}^{2}=0.16, \mathrm{p}<0.001\right)$ during the brooding stage. There was no change in VTD $\left(\mathrm{R}^{2}=0.02\right.$, $p=0.191)$, but the total dive time increased $\left(R^{2}=0.11\right.$, $\mathrm{p}<0.001$ ) during the study period. No temporal changes in these parameters were found at KER and CRO. Food load was linearly and positively related to the date of the daily trips at all the study sites (data not shown), suggesting time changes in foraging behaviour.

\section{Diet}

A total of 92522,158381 and 116563 prey items were recovered from the 34, 36 and 27 food samples from AMS, KER and CRO respectively. Overall they contained 32, 12 and 16 different taxa respectively. Crustaceans were by far the most numerous prey in the diet of rockhopper penguins during the brooding period $(90.4 \pm 10.9,99.6 \pm 0.5$ and $94.9 \pm 4.9 \%$ at AMS, KER and CRO respectively). One species of euphausiid shrimp was the main item at each site, Thysanoessa gregaria $(83.4 \%$ of the number of prey, total for all samples pooled) at AMS, and Euphausia vallentini at $\operatorname{KER}(82.5 \%)$ and CRO (87.8\%). Other significant items ( $>1 \%$ by number) were unidentified copepods $(6.8 \%$, probably prey secondarily ingested), the ommastrephid squid Todarodes filippovae $(4.8 \%)$ and the cranchiid squid Teuthowenia pellucida (3.2\%) at AMS, the amphipod Themisto gaudichaudii (7.5\%), the copepod Paraeuchaeta antarctica (4.8\%) and the mysid shrimp Mysidetes morbihanensis (4.8\%) at KER, and Thysanoessa sp. (7.0\%) and unidentified postlarval fish $(4.7 \%)$ at CRO.

Crustaceans dominated the diet by fresh mass at KER and CRO, but not at AMS $(43.7 \pm 29.6,97.1 \pm 5.9$ and $95.1 \pm 4.6 \%$ at AMS, KER and CRO respectively; ANOVA: $\left.F_{2,94}=106.9, \mathrm{p}<0.001\right)$. Fish was more important in food samples from AMS (12.2 $\pm 14.7,2.9 \pm$ 5.9 and $4.3 \pm 4.2 \%$ at AMS, KER and CRO respectively; $\left.F_{2,94}=11.6, \mathrm{p}<0.001\right)$. Juvenile squid co-occurred with crustaceans as the main prey by mass at AMS, were minor items at CRO and were not found at KER (43.9 \pm 25.8, 0 and $0.6 \pm 1.5 \%$ at AMS, KER and CRO respectively; $F_{2,94}=153.0, \mathrm{p}<0.001$ ). At AMS, the mass of squid in food samples was linearly and positively related to the date of the foraging trip $(\mathrm{m}=-1229.06+$ $4.41 \times$ Day of the year, $\left.\mathrm{R}^{2}=0.27, \mathrm{p}=0.002\right)$.

\section{DISCUSSION}

\section{General comments and comparison with previous data on rockhopper penguins}

Until recently, little was known about the foraging and diving behaviour of rockhopper penguins. Diving behaviour of the subspecies filholi has been investigated in late chick-rearing at the Crozet Archipelago 
on 1 individual only (Eudyptes chrysocome filholi, not E. c. chrysocome as stated in Wilson et al. 1997), and a more complete study was performed at Macquarie Island over 2 consecutive years (Hull 2000). Females fitted with TDRs at the latter locality stayed at sea on average 6.4 to $7.0 \mathrm{~d}$ during the brooding period (Hull 1999a, 2000). This long duration contrasts with the data collected in the present study and the typical pattern of daily trips described for eudyptid penguins (Warham 1975), including rockhopper penguins (Warham 1963, Brown 1987a). Increasing foraging trip duration possibly resulted from the deleterious effect of using non-streamlined TDRs (Hull 1997, 1999a).

The diurnal foraging behaviour enforces a limited foraging range for female rockhopper penguins during the brooding period. Birds from AMS, KER and CRO foraged mostly within $10 \mathrm{~km}$ of their colonies, which is in agreement with a previous estimation at AMS (Cherel et al. 1999), but not with those at Marion (4 to $157 \mathrm{~km}$ ) and Macquarie $(104 \mathrm{~km}$ ) islands (Brown 1987a, Hull 1999a). Again, the difference is due to unusually long trips recorded at the latter locality. The characteristics of dives ( $>6 \mathrm{~m}$ ) recorded at Macquarie Island during the whole breeding season (Hull 2000) are within the range of those foraging dives we recorded during the brooding period. The only important difference is the duration of the longest dive performed at Macquarie (11 min), a value much higher than those recorded in previous work (Wilson et al. 1997, Cherel et al. 1999, present study). An 11 min dive seems improbable for a species of this size (Schreer \& Kovacs 1997), and it probably arose from the concatenation of several consecutive shorter dives that were not differentiated during software analysis (Kirkwood \& Robertson 1997a, Tremblay \& Cherel unpubl.).

Foraging ecology of female rockhopper penguins was investigated on 2 subspecies during 3 successive breeding seasons at AMS, KER and CRO, as it was not feasible to work on the 3 sites during the same season. We therefore cannot exclude the possibility that at least a part of inter-site differences in foraging behaviour was due to subspecies-year-season confounding factors. However, our main goal was to study foraging behaviour in contrasting marine environments, whatever the causes of the differences among them were. Temporal variation in penguin foraging ecology has been found using TDRs both within (Williams et al. 1992, Robinson \& Hindell 1996, Bethge et al. 1997, Kirkwood \& Robertson 1997b, Cherel et al. 1999, Moore et al. 1999) and between (Watanuki et al. 1993, Hull 2000) seasons. Nevertheless, a comparison between 2 successive brooding periods in 1995 (Cherel et al. 1999) and 1996 (present study) using the same methodology showed little variation in the foraging behaviour of female rockhopper penguins from AMS.
The duration of daily foraging trips was identical, females consistently foraged at the same depths, and they brought identical food masses back to their chicks (consisting of the same prey species) during the $2 \mathrm{yr}$. This suggests similar environmental conditions in waters surrounding AMS during the 2 brooding stages. This is supported by mean sea surface temperatures (SST) which were similar during October 1995 and 1996 (13 to $\left.14^{\circ} \mathrm{C}\right)$. The 2 seasons were not unusual as the mean SST anomalies were weak in both years $\left(-0.2^{\circ} \mathrm{C}\right)$ (Integrated Global Ocean Services System, IGOSS Products Bulletin). At KER and CRO, the mean SST was 4 to $5^{\circ} \mathrm{C}$ in January 1998 and 7 to $8^{\circ} \mathrm{C}$ in January 1999, corresponding to average anomalies of 0.0 and $+2.0^{\circ} \mathrm{C}$ respectively. The positive warm anomaly at $\mathrm{CRO}$ was associated with a decrease in chlorophyll concentration when compared to January 1998 ( 0.3 to 0.5 vs 0.5 to $1 \mathrm{mg} \mathrm{m}^{-3}$ ). As warm SST anomalies are known to decrease breeding performance and body condition of seabirds in the Southern Indian Ocean (Guinet et al. 1998), it is possible that some aspects of the foraging behaviour of penguins at CRO in January 1999 differed from those of a normal year with no thermal anomalies. However, rockhopper penguins fed mainly on Euphausia vallentini in January 1999, as previously found at several subantarctic localities (Cooper et al. 1990, Hull 1999b), including the Crozet Islands in January 1981 (Ridoux 1994).

\section{Foraging patterns}

Penguin species can be split into 2 groups according to their foraging patterns during the chick-rearing period. The largest emperor Aptenodytes forsteri and king $A$. patagonicus penguins make long foraging trips (several days), while the other species make shorter trips closer to the colonies, i.e. several hours to a few days (Wilson 1995). During the brooding period, female rockhopper penguins appeared to follow a fixed schedule, departing in the early morning and returning to the colony in the late afternoon, with no differences in the duration of the daily trips (about 11 to $12 \mathrm{~h}$ ) at AMS, KER and CRO. In addition, birds foraging in more open waters at AMS and CRO made a few overnight trips, whereas the birds feeding in more coastal waters at KER did not. Since penguins are mainly visual predators (Wilson 1995), a restricted foraging time could have occurred at AMS, as trip duration averaged $93 \%$ of the daylight hours, but not at KER and CRO where $25 \%$ of the daytime remained available for increasing the duration of foraging trips.

During the brooding period, the body mass of foraging females decreased in a similar way at AMS, KER and CRO. Females thus relied on their endogenous 
reserves while making short foraging trips to feed their chicks at a high rate; a situation also known to occur in other penguin species (Croxall 1984, Wilson et al. 1991) and, with a different strategy, in some procellariiform seabirds (Weimerskirch 1990, Weimerskirch \& Lys 2000). Given the short duration of trips and the short foraging range at the 3 sites, rockhopper penguins must depend on predictable and closely located marine resources when rearing small chicks. These prey species are mainly euphausiids and, depending upon water mass, are Thysanoessa gregaria in subtropical waters and the Euphausia vallentini further south.

\section{Flexible diving parameters and behaviour}

Diving behaviour of penguins has been reported to vary according to physical parameters (Wilson et al. 1993, Watanuki et al. 1997, Rodary et al. 2000), prey species and food availability (Croxall et al. 1988, Watanuki et al. 1993, Radl \& Culik 1999), sex (Bethge et al. 1997, Clarke et al. 1998), breeding stage and energy demands (Tremblay et al. 1997, Charrassin et al. 1998), and seasons and years (Kirkwood \& Robertson 1997b, Moore et al. 1999, Hull 2000). The ultimate factors explaining those behavioural variations are, however, difficult to pinpoint, as they are often mixed and covariate. In order to reduce sources of variation, we considered the same species at the same breeding stage; additionally we considered only females performing short trips to feed the chicks. Thus, differences in diving behaviour of female rockhopper penguins were likely to be due to phenotypic plasticity in response to different marine environments and/or to genetically based local adaptations, and not to other confounding factors.

The 3 principal components of the PCA clearly segregated daily foraging trips into 3 groups corresponding to each of the 3 study sites. Overall, PC1 (diving mode) indicated that birds from AMS dived less deeply, had shorter dive duration and bottom time, and were less active during less efficient dives than birds from KER and CRO. On the other hand, PC3 (variation of behaviour) showed that birds from KER segregated from those from AMS and CRO, by performing more uniform foraging dives with less variability in dive depth, duration and activity index. The PCA emphasised that most of the characteristics of daily trips and all the characteristics of foraging dives varied according to the study sites, thereby stressing the importance of distinct environments in shaping the foraging behaviour of seabirds. While it is difficult to compare our analysis with other studies on penguins, large variations in dive depth and duration, as noted for female rockhopper penguins (from $23 \mathrm{~m} / 78 \mathrm{~s}$ at AMS to
$40 \mathrm{~m} / 102 \mathrm{~s}$ at CRO), have been noted only in the Adélie penguin Pygoscelis adeliae (Watanuki et al. 1993, Rodary et al. 2000) and the king penguin (Moore et al. 1999). As the foraging strategies of these 3 species are different, this suggests that all penguin species are able to exhibit contrasted behaviours depending on environmental changes in time and space.

Bimodality in dive duration and dive depth was found in most diving birds and mammals (Boyd \& Croxall 1996). Indirect evidence supports the view that the 2 modes of short and long dives in penguins are within the aerobic dive limit, i.e. only very long and rare dives are associated with anaerobiosis (Boyd \& Croxall 1996, Ponganis et al. 1997). At AMS, KER and CRO, there was an almost linear relationship between PDI and dive duration $<150 \mathrm{~s}$, and dives longer than $150 \mathrm{~s}$ accounted for an insignificant number $(<1 \%)$ of dives, suggesting that female rockhopper penguins performed mainly aerobic dives at the 3 sites. Interestingly, PDI for a given depth was always shorter at AMS than at KER and CRO. This suggests that birds from AMS were physiologically better able to replenish their oxygen stores or that, as suggested for alcids (Monaghan et al. 1994, Davoren 2000), they postponed full recovery from the physiological effects of diving until foraging bouts were finished. The latter was, however, unlikely to occur because in contrast to alcids, rockhopper penguins continuously dived during the daily trips, as indicated by their high dive frequency, total time spent submerged and the small number of extended PDI. Geographical variation in physiological traits have been little investigated, but the size of body organs, including heart, is known to vary among sites and ecological correlates in seabirds (Hilton et al. 2000). Accordingly, the heart of rockhopper penguins from AMS presents a right ventricular hypertrophy, suggesting an increased lung perfusion during surface recovery leading to shorter PDI when compared to other penguin species (Drabek \& Tremblay 2000). Whether or not a difference in heart morphology occurs between the subtropical (AMS) and subantarctic (KER and $\mathrm{CRO}$ ) rockhopper penguins however remains to be determined, but it is noticeable that the northern subspecies is larger than the subantarctic one (Table 4). A possible benefit of being larger at AMS could be being better at catching large and mobile prey like squid (Tremblay et al. 1997, present study) and fish later in the breeding season (Tremblay et al. 1997).

\section{Food mass and chick growth rate}

Food mass brought ashore by female rockhopper penguins was markedly different among sites, being much lower at AMS than at KER and CRO. Such a difference agrees with the finding that birds from the 
northern subspecies breeding either in the Atlantic (Klages et al. 1988) or the Indian (Tremblay et al. 1997, Cherel et al. 1999) Oceans provide less food to the chicks than adults of the 2 southern subspecies (Cooper et al. 1990). Composition and mass of food loads have been related to the availability of prey for many seabirds, including penguins (Croxall et al. 1999). No data on macrozooplankton stocks is available at the 3 sites, but it was recently found that mesozooplankton biomass was elevated in the Golfe du Morbihan at KER when compared to shelf waters at CRO or the oceanic sectors of the Indian Ocean (Razouls et al. 1997). Thus, food load of female rockhopper penguins probably reflected the level of local marine resources at the different localities, being lower at AMS, medium at CRO and higher at KER, as also suggested by chlorophyll concentrations and zooplankton biomass in previous studies (see above).

The growth of seabird chicks can vary both temporally and geographically and may be sensitive to local availability of prey (Cairns 1987, Montevecchi 1993). Early growth in chicks of the rockhopper penguin integrates the temporal foraging effort of the females over the whole brooding period. In agreement with differences in food loads of females, growth rate and chick body mass at 20 to $25 \mathrm{~d}$ were lower at AMS, but were similar at KER and CRO. This again suggests lower availability of resources for rockhopper penguins rearing chicks at AMS. At each site, chick body mass in the foraging colony was identical to that in the control colony at the beginning of the study period, but over the whole brooding period, a slight difference progressively developed between the 2 colonies. A probable explanation was that increasingly more females were fitted with TDRs and flushed to collect stomach contents. This would have lead to a gradual slowing down in the growth of more and more chicks by deleting a single meal for each chick during the study period. This difference in early growth was however likely to be buffered at the crèche stage when both females and males fed their chicks, as previously demonstrated in Adélie penguins (Robertson et al. 1994).

Food mass increased with chick age at KER and CRO, but not at AMS, indicating that females at KER and $\mathrm{CRO}$ adapted to the rapid increase in energy requirements of chicks during the first weeks of life (Brown 1987 b) by increasing food loads. Food mass however increased with dates at the 3 localities, suggesting that birds from AMS responded more to a change in the marine environment than to the chick energy demand per se during the study period. Accordingly, the mass of squid in food samples from AMS was linearly and positively related to the date of the foraging trip. The energy content of squid being less than that of crustaceans and fish, we calculated the calorific value of meals assuming the energy equivalent of $4.35,3.47$ and $3.97 \mathrm{~kJ} \mathrm{~g}^{-1}$ for crustaceans, squid and fish, respectively (Croxall et al. 1984). Considering time-changes in food mass and composition, the energy content of meals increased from 359 to 470,790 to 1034 , and 609 to $843 \mathrm{~kJ}$ between the first and second half of the brooding period at $A M S, K E R$ and $C R O$ respectively. The difference (111, 244 and $234 \mathrm{~kJ}$ respectively) was much lower at AMS, thus explaining the slower rate of growth at this locality at the end of the study period. Chicks from AMS, however, partially compensated for a lower provisioning rate by having a $10 \%$ higher crude growth efficiency (i.e. grams increase in body mass relative to mass of food ingested $\times 100$ ) than at KER and CRO (35.5, 23.1 and 26.0\% respectively). This suggests that chicks from AMS had a better assimilation efficiency, a physiological response that follows the predictions of the 'digestive adaptation paradigm' which indicates that underfeeding is compensated by an increasing digestive efficiency (Konarzewski \& Starck 2000, Salihoglu et al. 2001). Another non-exclusive explanation is that warmer air temperatures reduce thermoregulation costs at AMS in comparison with CRO and KER, thus decreasing metabolic demand of the chicks at the former locality.

\section{Foraging effort}

Because the energetic costs of foraging activities of diving animals are difficult to quantify directly in the field (Butler \& Jones 1997), several indices of foraging effort have been defined for diving birds and pinnipeds, the most commonly used being the number and duration of foraging trips, the total dive time, the number of dives and their frequency, and the vertical travel distance (Williams \& Rothery 1990, Watanuki et al. 1993, Bengtson et al. 1993, Horning \& Trillmich 1997). Several indices have not been generally investigated in conjunction, therefore precluding their critical evaluation within and between studies.

A comparison of foraging effort indices during daily trips at AMS, CRO and KER showed no differences in trip duration and total dive time at the 3 sites. Dive frequency and the total number of dives decreased, but the mean dive depth increased, at AMS, KER and CRO, the result being a $20 \%$ higher VTD at CRO than at AMS and KER. PCA indicated that PC2, which included several indices of foraging effort, separated trips between the 3 sites. PC2 values were significantly higher at AMS, medium at KER and lower at CRO. It was noticeable that foraging effort was higher overall at AMS where prey availability was presumably the lowest, however such differences were small. PC2 values from the 3 sites overlapped extensively (Fig. 9). 
Another indirect index of foraging effort was the decrease in mass of the females during the brooding period. Daily loss in body mass was similar at the 3 sites, thus emphasising the fact that foraging effort was not greatly different during the brooding period at AMS, KER and CRO, despite large variations in the food loads of females by the end of the period. This suggests that female rockhopper penguins foraged nearly to their maximum potential, and that birds from AMS could not further increase their foraging effort to collect more food. As with Adélie penguins (Watanuki et al. 1993), female rockhopper penguins probably make it a priority to maintain body condition for their own future survival at the expense of increasing energy expenditure for chick production. Maintaining trip duration at the cost of bringing back smaller meals when environmental conditions are poor is in agreement with one of the few studies that have simultaneously and independently measured prey abundance and foraging parameters of seabirds (Croxall et al. 1999). Other studies on penguins have shown a much higher plasticity in trip duration (Radl \& Culik 1999), generally associated with changes in food loads, increasing trip duration and decreasing food load (or not) when marine resources were (presumably) less available (Irvine et al. 2000). Conversely, when food is presumably not limited, birds performing longer trips return with larger meals, which is in agreement with the central place foraging theory (Watanuki et al. 1997, but see Ainley et al. 1998).

\section{Foraging strategies and the marine environment}

We found differences in foraging strategies of female rockhopper penguins at AMS, KER and CRO, the differences being linked to contrasting marine environments. Birds from AMS began to forage close to the colony but they performed more travelling dives than at KER and CRO. They dived at a high rate, the large number of short and shallow dives including a few IDZ dives that peaked at 15 to $25 \mathrm{~m}$. The inability of females at AMS to adjust food load to chick age contrasted with the results at the 2 subantarctic localities. However, birds had the capacity to adjust food load size by feeding upon a new food source (squid) in addition to euphausiids, while undertaking an increasing number of shallower dives.

At KER, female rockhopper penguins performed a large number of IDZ dives at 25 to $45 \mathrm{~m}$. This concurs with the recent description of benthic dives (Tremblay \& Cherel 2000). Birds dived repeatedly in dense epibenthic food patches, which explains the smaller vertical distance swam per depth wiggle at KER than at AMS and CRO. While their overall foraging effort
(PC2) was the lowest at KER, these birds had the highest food loads, highest chick growth rate and moreover they began to forage closer to the colony. By contrast, birds from CRO foraged in the water column, where they performed longer and deeper dives, including a high percentage of IDZ dives between 40 and $60 \mathrm{~m}$. Presumably, patches of food located at deep depths forced penguins to perform dives at depths deeper than those for which the highest diving efficiency was found, thus emphasizing the constraint of prey location for shaping foraging behaviour of seabirds. However, birds at CRO, like those at KER, were able to increase food mass with chick age. This suggests, together with medium values in food loads and chick growth rates, that prey availability in neritic subantarctic waters (CRO) was intermediate between that found in oceanic tropical waters (AMS) and that found in a coastal subantarctic habitat (KER).

In conclusion, foraging behaviour of female rockhopper penguins appeared to vary extensively between the 3 sites during the brooding period. The present study therefore emphasises the importance of behavioural plasticity in space and time and suggests that it is a fundamental trait of the life history of seabirds living in a variable environment. It stresses the need for detailed investigations over several years and/or sites, together with independent measurements of marine resources. By underlining the sensitivity of penguins to their environment, the study shows the potential of using top predators to monitor marine resources. Finally, studies using TDRs coupled with the quantification of energy expenditure are required to critically interpret changes in the indices of foraging effort (Arnould et al. 1996, Costa \& Gales 2000), and to better understand how air-breathing vertebrates allocate time and energy to different activities in relation to changes in prey distribution and abundance, within the constraint of rearing chicks.

Acknowledgements. The authors are especially grateful to C. Trouvé, D. Pinaud and J. Spaggiari for their help in diet analysis, and to N. Voss for identifying juvenile cranchiid squids. They thank S. Caule, O. Duriez, T. Guionnet, A. Hoecker, G. Juin, J. Martin, D. Secondi, S. Shaffer and L. Zimmerman for their help in the field, and L. Dubroca for downloading chlorophyll data. The authors would like to thank the SeaWIFS project (Code 970.2) and the Goddard Earth Sciences Data and Information Services Center/Distributed Active Archive Center (Code 902) at the Goddard Space Flight Center, Greenbelt, MD 20771, for the production and distribution of environmental data. We are also grateful to anonymous referees for fruitful comments and their help in correcting the English. This work was supported financially and logistically by the Institut Français pour la Recherche et la Technologie Polaires (Programme No 109) and the Terres Australes et Antarctiques Françaises. 


\section{LITERATURE CITED}

Ainley DG, Wilson PR, Barton KJ, Ballard G, Nur N, Karl B (1998) Diet and foraging effort of Adélie penguins in relation to pack-ice conditions in the southern Ross Sea. Polar Biol 20:311-319

Arnould JPY, Boyd IL, Speakman JR (1996) The relationship between foraging behaviour and energy expenditure in Antarctic fur seals. J Zool Lond 329:769-782

Baker AdeC, Boden BP, Brinton E (1990) A practical guide to the euphausiids of the world. Natural History Museum Publications, London

Ballard G, Ainley DG, Ribic CA, Barton KR (2001) Effect of instrument attachment and other factors on foraging trip duration and nesting success of Adélie penguins. Condor 103:481-490

Bannasch R, Wilson RP, Culik B (1994) Hydrodynamic aspects of design and attachment of a back-mounted device in penguins. J Exp Biol 194:83-96

Bengtson JL, Croll DA, Goebel ME (1993) Diving behaviour of chinstrap penguins at Seal Island. Antarct Sci 5:9-15

Bethge P, Nicol S, Culik BM, Wilson RP (1997) Diving behaviour and energetics in breeding little penguins (Eudyptula minor). J Zool Lond 242:483-502

Boyd IL, Croxall JP (1996) Dive durations in pinnipeds and seabirds. Can J Zool 74:1696-1705

Brown CR (1987a) Traveling speed and foraging range of macaroni and rockhopper penguins at Marion Island. J Field Ornithol 58:118-125

Brown CR (1987b) Energy requirements for growth and maintenance in macaroni and rockhopper penguins. Polar Biol 8:95-102

Butler PJ, Jones R (1997) Physiology of diving of birds and mammals. Physiol Rev 77:837-899

Cairns DK (1987) Seabirds as indicators of marine food supplies. Biol Oceanogr 5:261-271

Chappell MA, Shoemaker VH, Janes DN, Bucher TL, Maloney SK (1993) Diving behavior during foraging in Adélie penguins. Ecology 74:1204-1215

Charrassin JB, Bost CA, Pütz K, Lage J, Dahier T, Zorn T, Le Maho Y (1998) Foraging strategies of incubating and brooding king penguins Aptenodytes patagonicus. Oecologia 114:194-201

Cherel Y, Tremblay Y, Guinard E, Georges JY (1999) Diving behaviour of female northern rockhopper penguins, Eudyptes chrysocome moseleyi, during the brooding period at Amsterdam Island (Southern Indian Ocean). Marine Biol 134:375-385

Clarke J, Manly B, Kerry K, Gardner H, Franchi E, Corsolini S, Focardi S (1998) Sex differences in Adélie penguin foraging strategies. Polar Biol 20:248-258

Cooper J, Brown CR, Gales RP, Hindell MA and 6 others (1990) Diets and dietary segregation of crested penguins (Eudyptes). In: Davis LS, Darby JT (eds) Penguin biology. Academic Press, San Diego, p 131-156

Costa DP, Gales NJ (2000) Foraging energetics and diving behavior of lactating New Zealand sea lions, Phocarctos hookeri. J Exp Biol 203:3655-3665

Croxall JP (1984) Seabirds. In: Laws RM (ed) Antarctic ecology. Academic Press, London, p 534-616

Croxall JP, Ricketts C, Prince PA (1984) Impact of seabirds on marine resources, especially krill, of South Georgia waters. In: Causey G, Rahn H (eds) Seabird energetics. Plenum Press, New York, p 285-317

Croxall JP, Davis RW, O'Connell MJ (1988) Diving patterns in relation to diet of gentoo and macaroni penguins at South Georgia. Condor 90:157-167
Croxall JP, Briggs DR, Kato A, Naito Y, Watanuki Y, Williams TD (1993) Diving pattern and performance in the macaroni penguin Eudyptes chrysolophus. J Zool Lond 230: $31-47$

Croxall JP, Reid K, Prince PA (1999) Diet, provisioning and productivity responses of marine predators to differences in availability of Antarctic krill. Mar Ecol Prog Ser 177: $115-131$

Davoren GK (2000) Variability in foraging in response to changing prey distributions in rhinoceros auklets. Mar Ecol Prog Ser 198:283-291

Drabek CM, Tremblay Y (2000) Morphological aspects of the heart of the northern rockhopper penguin (Eudyptes chrysocome moseleyi): possible implication in diving behavior and ecology? Polar Biol 23:812-816

Gales RP (1987) Validation of the stomach-flushing technique for obtaining stomach contents of penguins. Ibis 129: 335-343

Guinet C, Chastel O, Koudil M, Durbec JP, Jouventin P (1998) Effects of warm sea-surface temperature anomalies on the blue petrel at the Kerguelen Islands. Proc R Soc Lond B 265:1001-1006

Foxton P (1956) The distribution of the standing crop of zooplankton in the Southern Ocean. Disc Rep 28:191-236

Hilton GM, Lilliendahl K, Solmundsson J, Houston DC, Furness RW (2000) Geographical variation in the size of body organs in seabirds. Funct Ecol 14:369-379

Horning M, Trillmich F (1997) Ontogeny of diving behavior in the Galapagos fur seal. Behaviour 134:1211-1257

Hull CL (1997) The effect of carrying devices on breeding royal penguins. Condor 99:530-534

Hull CL (1999a) The foraging zones of breeding royal (Eudyptes schlegeli) and rockhopper (E. chrysocome) penguins: an assessment of techniques and species comparison. Wildl Res 26:789-803

Hull CL (1999b) Comparison of the diets of breeding royal (Eudyptes schlegeli) and rockhopper (Eudyptes chrysocome) penguins on Macquarie Island over three years. J Zool Lond 247:507-529

Hull CL (2000) Comparative diving behaviour and segregation of the marine habitat by breeding royal penguins, Eudyptes schlegeli, and eastern rockhopper penguins, Eudyptes chrysocome filholi, at Macquarie Island. Can J Zool 78:333-345

Hurlbert SH (1984) Pseudoreplication and the design of ecological field experiments. Ecol Monogr 54:187-211

Irvine LG, Clarke JR, Kerry KR (2000) Low breeding success of the Adélie penguin at Bérchevaise island in the 1998/99 season. CCAMLR Sci 7:151-167

Kirkwood R, Robertson G (1997a) The foraging ecology of female emperor penguins in winter. Ecol Monogr 67: $155-176$

Kirkwood R, Robertson G (1997b) Seasonal change in the foraging ecology of emperor penguins on the Mawson Coast, Antarctica. Mar Ecol Prog Ser 156:205-223

Klages N, De Brooke M, Watkins BP (1988) Prey of northern rockhopper penguins at Gough Island, South Atlantic Ocean. Ostrich 59:162-165

Konarzewski M, Starck JM (2000) Effects of food shortage and oversupply on energy utilization, histology, and function of the gut in nestling song thrushes (Turdus philomelos). Physiol Biochem Zool 73:416-427

Kooyman GL, Kooyman TG (1995) Diving behavior of emperor penguins nurturing chicks at Coulman Island, Antarctica. Condor 97:536-549

Kooyman GL, Cherel Y, Le Maho Y, Croxall JP, Thorson PH, Ridoux V, Kooyman CA (1992) Diving behavior and 
energetics during foraging cycles in king penguins. Ecol Monogr 62:143-163

Labat JP, Mayzaud P, Dallot S, Errhif A, Razouls S, Sabini S (2002) Mesoscale distribution of zooplankton in the SubAntarctic Frontal system in the Indian part of the Southern Ocean: a comparison between optical plankton counter and net sampling. Deep-Sea Res I 49:735-749

Ledoyer M (1995) Mysidacés (Crustacea) de Kerguelen, Crozet et Bouvet (Océan Austral) récoltés par la Japonaise, le Marion-Dufresne (1972-82) et dans les contenus stomacaux d'oiseaux. J Nat Hist 29:601-618

Meyer WR, Bengtson JL, Jansen JK, Russel RW (1997) Relationships between brood size and parental provisioning performance in chinstrap penguins during the chick guard phase. Polar Biol 17:228-234

Monaghan P, Walton P, Wanless S, Uttley JD, Burns MD (1994) Effects of prey abundance on the foraging behaviour, diving efficiency and time allocation of breeding guillemots Uria aalge. Ibis 136:214-222

Montevecchi WA (1993) Birds as indicators of change in marine prey stocks. In: Furness RW, Greenwood JJD (eds) Birds as monitors of environmental change. Chapman \& Hall, London, p 217-266

Moore GJ, Wienecke B, Robertson G (1999) Seasonal change in foraging areas and dive depths of breeding king penguins at Heard Island. Polar Biol 21:376-384

Morrison ML, Ralph CJ, Verner J, Jehl JR Jr (1990) Avian foraging: theory, methodology, and applications. Stud Avian Biol 13:1-515

Park Y, Gambéroni L, Charriaud E (1993) Frontal structure, water masses, and circulation in the Crozet Basin. J Geophys Res 98:12361-12385

Peters G (1997) A new device for monitoring gastric $\mathrm{pH}$ in free-ranging animals. Am J Physiol 273:G748-G753

Ponganis PJ, Kooyman GL, Starke LN, Kooyman CA, Kooyman TG (1997) Post-dive blood lactate concentrations in emperor penguins, Aptenodytes forsteri. J Exp Biol 200: $1623-1626$

Radl A, Culik BM (1999) Foraging behaviour and reproductive success in Magellanic penguins (Spheniscus magellanicus): a comparative study of two colonies in southern Chile. Mar Biol 133:381-393

Razouls S, De Bovée F, Delille D, Fiala M, Mayzaud P (1997) Temporal variability of bacteria, phytoplankton and zooplankton assemblages of the sub-Antarctic Morbihan Bay (Kerguelen Archipelago). In: Battaglia B et al. (eds) Antarctic communities, species, structure and survival. Cambridge University Press, Cambridge, p 86-92

Ridoux V (1994) The diets and dietary segregation of seabirds at the subantarctic Crozet Islands. Mar Ornithol 22:1-192

Robertson G, Kent S, Seddon J (1994) Effects of the water offloading technique on Adélie penguins. J Field Ornithol 65:376-380

Robinson SA, Hindell MA (1996) Foraging ecology of gentoo penguins Pygoscelis papua at Macquarie Island during the period of chick care. Ibis 138:722-731

Rodary D, Wienecke BC, Bost CA (2000) Diving behavior of Adélie penguins (Pygoscelis adeliae) at Dumont D'Urville, Antarctica: nocturnal patterns of diving and rapid adaptations to changes in sea-ice condition. Polar Biol 23: 113-120

Salihoglu B, Fraser WR, Hofmann EE (2001) Factors affecting fledging weight of Adélie penguin (Pygoscelis adeliae) chick: a modeling study. Polar Biol 24:328-337

Schneppenheim R, Weigmann-Haass R (1986) Morphological and electrophoretic studies of genus Themisto (Amphi- poda: Hyperiidea) from South and North Atlantic. Polar Biol 6:215-225

Schreer JF, Kovacs KM (1997) Allometry of diving capacity in air-breathing vertebrates. Can J Zool 75:339-358

Tremblay Y, Cherel Y (1999) Synchronous underwater foraging behavior in penguins. Condor 101:179-185

Tremblay Y, Cherel Y (2000) Benthic and pelagic dives: a new foraging behaviour in rockhopper penguins. Mar Ecol Prog Ser 204:257-267

Tremblay Y, Guinard E, Cherel Y (1997) Maximum diving depths of northern rockhopper penguins (Eudyptes chrysocome moseleyi) at Amsterdam Island. Polar Biol 17: $119-122$

Warham J (1963) The rockhopper penguin, Eudyptes chrysocome, at Macquarie Island. Auk 80:229-256

Warham J (1975) The crested penguins. In: Stonehouse B (ed) The biology of penguins. MacMillan, London, p 189-269

Watanuki Y, Kato A, Mori Y, Naito Y (1993) Diving performance of Adélie penguins in relation to food availability in fast sea-ice areas: comparison between years. J Anim Ecol 62:634-646

Watanuki Y, Kato A, Naito Y, Robertson G, Robinson S (1997) Diving and foraging behaviour of Adélie penguins in areas with and without fast sea-ice. Polar Biol 17:296-304

Weimerskirch H (1990) Weight loss of Antarctic fulmars Fulmarus glacialoides during incubation and chick brooding. Ibis 132:68-77

Weimerskirch H, Lys P (2000) Seasonal changes in the provisioning behaviour and mass of male and female wandering albatrosses in relation to the growth of their chick. Polar Biol 23:733-744

Williams TD (1995) The penguins, Spheniscidae. Oxford University Press, Oxford

Williams TD, Rothery P (1990) Factors affecting variation in foraging and activity patterns of gentoo penguins (Pygoscelis papua) during the breeding season at Bird Island, South Georgia. J Appl Ecol 27:1042-1054

Williams TD, Briggs DR, Croxall JP, Naito Y, Kato A (1992) Diving pattern and performance in relation to foraging ecology in the gentoo penguin, Pygoscelis papua. J Zool Lond 227:211-230

Wilson RP (1995) Foraging ecology. In: Williams TD (ed) The penguins Spheniscidae. Oxford University Press, Oxford, p 81-106

Wilson RP, Culik BM, Adelung D, Spairani HJ, Coria NR (1991) Depth utilisation by breeding Adélie penguins, Pygoscelis adeliae, at Esperanza Bay, Antarctica. Mar Biol 109:181-189

Wilson RP, Puetz K, Bost CA, Culik BM, Bannasch R, Reins T, Adelung D (1993) Diel dive depth in penguins in relation to diel vertical migration of prey: whose dinner by candlelight? Mar Ecol Prog Ser 94:101-104

Wilson RP, Pütz K, Charrassin JB, Lage J (1995) Artifacts arising from sampling interval in dive depth studies of marine endotherms. Polar Biol 15:575-581

Wilson RP, Bost CA, Pütz K, Charrassin JB, Culik BM, Adelung D (1997) Southern rockhopper penguin Eudyptes chrysocome chrysocome foraging at Possession Island. Polar Biol 17:323-329

Woehler EJ (1995) Consumption of Southern Ocean marine resources by penguins. In: Dann P et al. (eds) The penguins. Surrey Beatty \& Sons, Chipping Norton, p 266-294

Ydenberg RC, Clark CW (1989) Aerobiosis and anaerobiosis during diving by western grebes: an optimal foraging approach. J Theor Biol 139:437-449

Submitted: February 11, 2002; Accepted: September 24, 2002 Proofs received from author(s): March 17, 2003 